\title{
Premotor Neuron Divergence Reflects Vocal Evolution
}

\author{
CCharlotte L. Barkan, ${ }^{1,2}$-Darcy B. Kelley, ${ }^{1,3}$ and $\odot$ Erik Zornik $^{2}$ \\ ${ }^{1}$ Doctoral Program in Neurobiology and Behavior, Columbia University, New York, New York 10032, ${ }^{2}$ Biology Department, Reed College, Portland, Oregon \\ 97202, and ${ }^{3}$ Department of Biological Sciences, Columbia University, New York, New York 10027
}

To identify mechanisms of behavioral evolution, we investigated the hindbrain circuit that generates distinct vocal patterns in two closely related frog species. Male Xenopus laevis and Xenopus petersii produce courtship calls that include a fast trill: trains of $\sim 60 \mathrm{~Hz}$ sound pulses. Although fast trill rates are similar, X. laevis fast trills have a longer duration and period than those of $X$. petersii. To pinpoint the neural basis of these differences, we used whole-cell patch-clamp recordings in a key premotor hindbrain nucleus (the Xenopus parabrachial area, $\mathrm{PB}_{\mathrm{X}}$ ) in ex vivo brains that produce fictive vocalizations, vocal nerve activity corresponding to advertisement call patterns. We found two populations of $\mathrm{PB}_{\mathrm{X}}$ neurons with distinct properties: fast trill neurons (FTNs) and early vocal neurons (EVNs). FTNs, but not EVNs, appear to be intrinsically tuned to produce each species' call patterns because: (1) X. laevis FTNs generate longer and slower depolarizations than $X$. petersii FTNs during their respective fictive vocalizations, (2) current steps in FTNs induce burst durations that are significantly longer in $X$. laevis than $X$. petersii, and (3) synaptically isolated FTNs oscillate in response to NMDA in a species-specific manner: longer and slower in X. laevis than in $X$. petersii. Therefore, divergence of premotor neuron membrane properties is a strong candidate for generating vocal differences between species.

Key words: central pattern generator; evolution; motor circuit; parabrachial area; vocal communication; Xenopus

\section{Significance Statement}

The vertebrate hindbrain includes multiple neural circuits that generate rhythmic behaviors including vocalizations. Male African clawed frogs produce courtship calls that are unique to each species and differ in temporal patterns. Here, we identified two functional subtypes of neurons located in the parabrachial nucleus: a hindbrain region implicated in vocal and respiratory control across vertebrates. One of these neuronal subtypes exhibits distinct properties across species that can account for the evolutionary divergence of song patterns. Our results suggest that changes to this group of neurons during evolution may have had a major role in establishing novel behaviors in closely related species.

\section{Introduction}

How does behavioral diversity arise during evolution? Temporal features of motor behaviors are controlled centrally by finely tuned neural circuits. Understanding how species-specific behaviors arise requires identifying the neural circuits that control these behaviors and uncovering the mechanisms that account for behavioral divergence. Behavioral variation in recently diverged species likely reflects small differences in the underlying neural circuits (Katz and Harris-Warrick, 1999; Katz, 2016) and thus provides a natu-

Received Jan. 11, 2018; revised April 9, 2018; accepted April 28, 2018.

Author contributions: C.L.B. wrote the first draft of the paper; C.L.B., D.B.K., and E.Z. edited the paper; C.L.B. D.B.K., and E.Z. designed research; C.L.B. and E.Z. performed research; C.L.B. and E.Z. analyzed data; C.L.B., D.B.K., and E.Z. wrote the paper.

This work was supported by the National Science Foundation (Graduate Research Fellowship Program Grant to C.L.B.), the National Institutes of Health (Grant NS091977 to E.Z. and Grant NS23684 to D.B.K.), the Weintraub Chair (research funds to D.B.K.), and Reed College (start-up funds to E.Z.). We thank Albyn Jones for statistical consultation.

The authors declare no competing financial interests.

Correspondence should be addressed to Erik Zornik, Biology Department, Reed College, 3203 S.E. Woodstock Blvd., Portland, 0R 97202. E-mail: ezornik@reed.edu.

DOI:10.1523/JNEUROSCI.0089-18.2018

Copyright $\odot 2018$ the authors $\quad 0270-6474 / 18 / 385325-13 \$ 15.00 / 0$ ral framework in which to explore how distinct behaviors evolve from homologous components.

During speciation, changes either to network properties or to intrinsic cellular properties of motor circuits could lead to behavioral divergence. Network properties such as connectivity, neuromodulation, synaptic strength, and valence have been shown to account for behavioral variation across species and between conspecifics (Chiang et al., 2006; Goaillard et al., 2009; Newcomb and Katz, 2009; Baltzley et al., 2010; Bumbarger et al., 2013). Intrinsic cellular properties such as ion channel expression and current density have been shown to correlate with behavioral differences between conspecifics (Rabbah and Nadim, 2005; Goaillard et al., 2009). However, few species-specific cellular properties underlying distinct behaviors have been identified. To identify discrete circuit properties that underlie behavioral differences, we investigated the premotor circuit that generates species-specific courtship vocalizations in two species of African clawed frogs, Xenopus laevis and Xenopus petersii.

Xenopus courtship vocalizations are highly stereotyped motor behaviors (Yamaguchi and Kelley, 2000; Tobias et al., 2011). As in other anurans, male Xenopus produce a species-specific adver- 


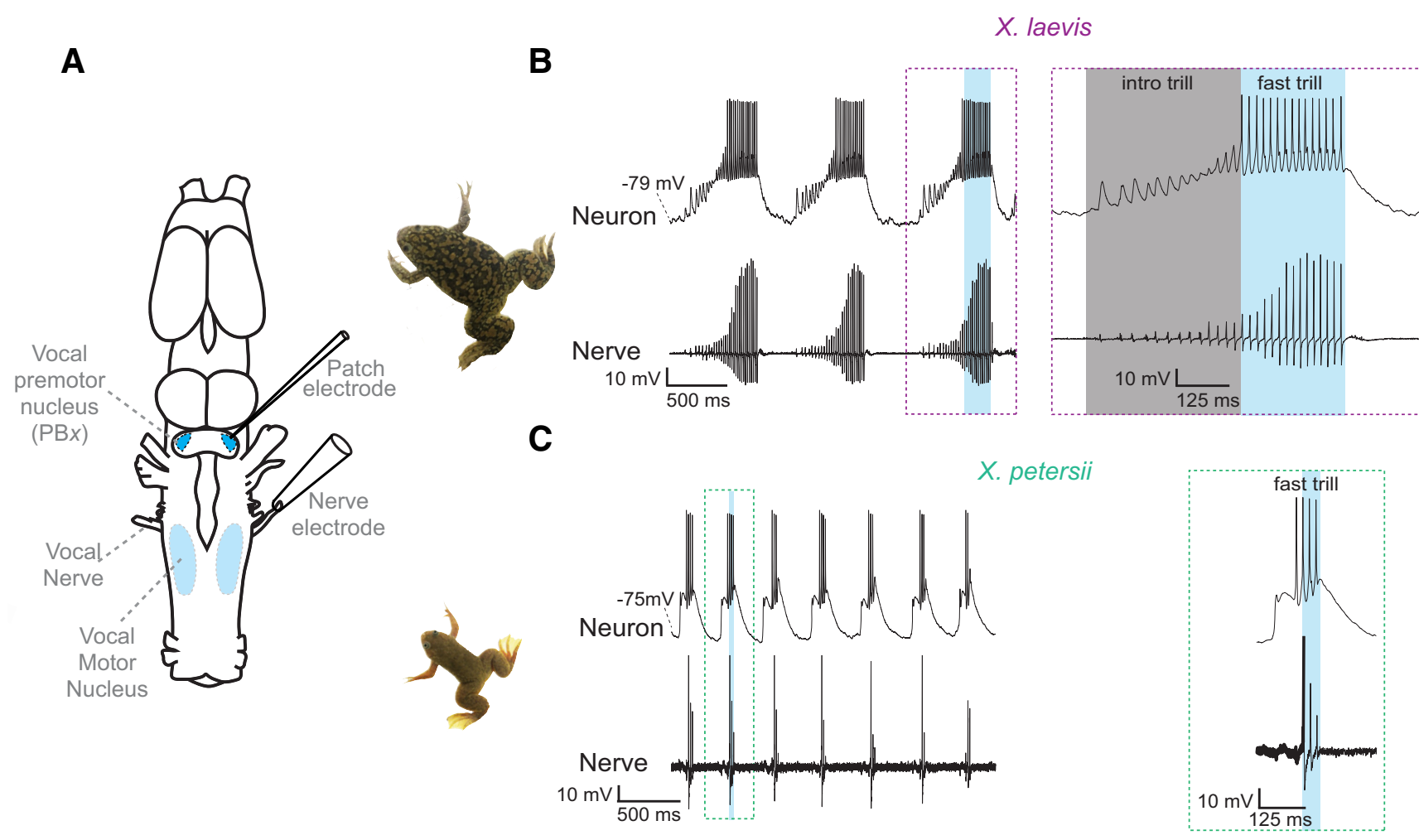

Figure 1. A vocal CPG underlies divergent vocalizations in $X$. Iaevis and $X$. petersii. $A$, Schematic representation of the known hindbrain vocal central pattern generator nuclei. The vocal motor nucleus (n) IX-X contains vocal motor neurons. These neurons send their axons via the vocal (laryngeal) nerve to the larynx, the vocal effector organ. Fictive calling can be recorded from the vocal nerve using a suction electrode. Premotor neurons in the Xenopus $\mathrm{PB}_{\mathrm{X}}$ project monosynaptically to the vocal motor nucleus. In $\mathrm{PB}_{\mathrm{X}}$, whole-cell electrodes can record activity associated with fictive calling. $B$, Representative example of $X$. laevis fictive calling consisting of a series of long, fast-rate CAP trills ( $\sim 60 \mathrm{~Hz}$; blue box, Nerve) and a simultaneously recorded premotor vocal neuron (Neuron). Temporally expanded recording (dashed box) of a single $X$. laevis call with introductory trill (gray box) and fast trill (blue box) and corresponding premotor neuron activity (right). C, Representative example of $X$. petersii fictive calling consisting of a series of brief, fast-rate CAP trills ( $\sim 60 \mathrm{~Hz}$, blue box, Nerve) and a simultaneously recorded premotor vocal neuron (Neuron). Temporally expanded recording (dashed box) of a single $X$. petersii fictive fast trill (blue box) and corresponding premotor neuron activity (right) are also shown.

tisement call that attracts conspecific female mates (Picker, 1983; Ryan and Rand, 1993; Gerhardt, 1994). In each species of the genus Xenopus, males produce a quantitatively unique advertisement call with distinct temporal and spectral features that serve as a species identifier (Tobias et al., 2011).

$X$. laevis and $X$. petersii diverged $\sim 8.5$ million years ago (Furman et al., 2015) and males in both species produce advertisement calls containing "fast trills," which consist of trains of rapid $(60 \mathrm{~Hz})$ sound pulses (Tobias et al., 2011). Although sound pulse rates within fast trills are similar between the two species, the duration and period of trills differ substantially: X. laevis calls have a longer duration and period than those of X. petersii (Barkan et al., 2017). Because $X$. laevis and X. petersii diverged relatively recently, we hypothesize that subtle vocal circuit changes might underlie their distinct call patterns.

In X. laevis and X. petersii, isolated brains (Fig. $1 A$ ) produce fictive vocal behavior, patterns of vocal nerve activity that correspond to in vivo call patterns (Fig. 1B,C, Nerve; Rhodes et al., 2007; Barkan et al., 2017). Previous work in X. laevis identified neurons in the premotor parabrachial area $\left(\mathrm{PB}_{\mathrm{X}}\right)$, which was initially called "DTAM" in Xenopus (Kelley et al., 1975; Schmidt, 1992) and the pretrigeminal nucleus in other anurans, with activity patterns that are tightly linked to fictive fast trills (Zornik and Yamaguchi, 2012; Lawton et al., 2017). A recent study in X. petersii and another related species, $X$. victorianus, showed that $\mathrm{PB}_{\mathrm{X}}$ activity (as measured with local field potentials) is also strongly correlated with fictive fast trills in these species (Barkan et al., 2017). Because these patterns persisted when $\mathrm{PB}_{\mathrm{X}}$ was synaptically isolated from the rest of the hindbrain vocal circuit (Barkan et al., 2017), we propose that $\mathrm{PB}_{\mathrm{X}}$ autonomously encodes species differences in call duration and period. Here, we used whole-cell patch-clamp recordings in $\mathrm{PB}_{\mathrm{X}}$ to determine whether species-specific tuning of premotor neurons could contribute to the production of distinct advertisement calls in X. laevis and X. petersii.

\section{Materials and Methods}

Animal care. Sexually mature X. laevis $(n=23)$ and X. petersii $(n=23)$ male frogs were used for all experiments. X. laevis were purchased from Nasco and X. petersii from Xenopus Express. Animals were group housed with a recirculating water system in PETG aquaria (Aquaneering) on a $12 \mathrm{~h} \mathrm{light} / 12 \mathrm{~h}$ dark schedule at $20^{\circ} \mathrm{C}$ and fed twice weekly. All animal care and experimental procedures conformed to guidelines of the National Institutes of Health and were approved by Reed College's Institutional Animal Care and Use guidelines (protocol no. 022017).

In vitro brain preparation. Frogs were deeply anesthetized by injection of $1.3 \%$ tricaine methanesulfonate (MS-222; Sigma-Aldrich; X. laevis: 500-700 $\mu \mathrm{l}, X$. petersii: $200 \mu \mathrm{l}$ ) into the dorsal lymph sac. Brains were rapidly dissected from the skull and placed in ice-cold saline containing the following (in mM): $96 \mathrm{NaCl}, 20 \mathrm{NaHCO}_{3}, 2 \mathrm{CaCl}_{2}, 2 \mathrm{KCl}, 0.5 \mathrm{MgCl}_{2}$, 10 HEPES, and 11 glucose, $\mathrm{pH} 7.8$, oxygenated with $99 \% \mathrm{O}_{2}$. After removal, brains were pinned to a silicone elastomer-lined recording dish (Sylgard; Dow Corning) and exposed to $22^{\circ} \mathrm{C}$ saline for $1 \mathrm{~h}$ before starting experiments. Compound action potentials (CAPs) were recorded from the posterior rootlet of cranial nerve IX-X, which contains the axons of the laryngeal motor neurons (Simpson et al., 1986), using an extracellular suction electrode. The extracellular local field potential was recorded in $\mathrm{PB}_{\mathrm{X}}$ using a carbon fiber electrode (300-500 k $\Omega$; Kation Scientific). 
The nerve and extracellular $\mathrm{PB}_{\mathrm{X}}$ signals were amplified 1000 times (models 1700 and 1800, respectively; A-M Systems), band-pass filtered $(10 \mathrm{~Hz}$ to $5 \mathrm{kHz}$ ), digitized at $10 \mathrm{kHz}$ (Digi-data 1440A; Molecular Devices), and acquired with Clampex software (Molecular Devices). The cerebellum and optic tectum were transected midsagittally (dorsal to the fourth ventricle and central canal) and reflected laterally to expose $\mathrm{PB}_{\mathrm{X}}$, located ventral to the cerebellum, just below the surface of the fourth ventricle (Zornik and Yamaguchi, 2012). Whole-cell electrodes were constructed with thick-walled borosilicate capillary glass $(1.5 \mathrm{~mm}$ outer diameter; $0.86 \mathrm{~mm}$ inner diameter), pulled with a Flaming/Brown style microelectrode puller (P1000; Sutter Instruments) and filled with intracellular solution containing the following (in $\mathrm{mM}$ ): $115 \mathrm{KCl}, 2 \mathrm{MgCl}_{2}, 2$ EGTA, 10 HEPES, $2 \mathrm{MgATP}$, and $0.2 \mathrm{NaGTP}$, pH 7.4. Positive pressure was applied to the electrode as it was lowered into the tissue with a motorized micromanipulator (MC1000e; Siskiyou). Neurons were detected by advancing electrodes slowly $(\sim 1 \mu \mathrm{m} / \mathrm{s})$ through the tissue between $\sim 50$ and $200 \mu \mathrm{m}$ below the ventricular surface until a rapid increase in resistance was detected. Positive pressure was then released, negative pressure was applied to achieve a gigaohm seal, and additional brief negative pressure was applied to achieve a whole-cell patch recording. To elicit fictive calling, saline superfusion was paused and serotonin was applied to the saline bath to achieve a final concentration of $60 \mu \mathrm{M}$. Serotonin was applied for no more than $5 \mathrm{~min}$, at which time saline superfusion was resumed. Premotor vocal cells were identified by their simultaneous activity with fictive nerve CAPs during serotonin application. Two-second square steps of positive and negative current were used to measure input resistance, capacitance, membrane time constant, action potential half-width, rheobase, sag index, spike rate, and spike burst duration (details below).

Pharmacology. To examine premotor vocal cells in the absence of synaptic connectivity, we applied tetrodotoxin (TTX) to a final concentration of $0.5 \mu \mathrm{M}$ for $15 \mathrm{~min}$ after obtaining a stable recording and functionally characterizing the neuron during fictive vocalization. We then applied NMDA to achieve an initial bath concentration of $25 \mu \mathrm{M}$. We continued to increase the NMDA concentration by $25 \mu \mathrm{M}$ every 15 min until stable depolarizing oscillations occurred $(12 \mathrm{X}$. petersii and $9 \mathrm{X}$. laevis cells). Final concentrations varied from 25 to $75 \mu \mathrm{M}$, but the effective dose did not depend on cell type or species. All neurons that were held stably throughout this protocol produced oscillations.

Analyses. The Clampfit software threshold search was used to detect spike times. If spikes occurred as doublets or triplets (Zornik and Yamaguchi, 2012), then the time of the first spike was used. Whole-cell activity associated with a minimum of 10 fictive calls was measured for each cell included in analyses. Input resistance was determined from the steadystate membrane potential resulting from a series of hyperpolarizing current steps between -50 and $-10 \mathrm{pA}$ (steps of $+10 \mathrm{pA}$ ) or between -100 and $-25 \mathrm{pA}$ (steps of $+25 \mathrm{pA}$ ). The slope of the voltage-current curve was used to calculate resistance. Sag index was measured as follows: [(minimum voltage during the maximum hyperpolarizing current step) - (steadystate voltage deflection in the final $500 \mathrm{~ms}$ of the current step)/steady-state voltage deflection] as described in Farries et al. (2005). Tau was measured by fitting a standard exponential decay equation to the average of 10 hyperpolarizing sweeps of -50 or $-100 \mathrm{pA}$. Tau and resistance were used to calculate capacitance. Further analyses were performed using custom-made MATLAB (The MathWorks) scripts. Bursts during current steps were defined as 2 or more subsequent spikes with an interval $<3 \times$ median spike interval for the entire sweep. If spiking persisted at a regular rate for the duration of the current step (i.e., no spike intervals $>3 \times$ median spike interval), it was considered as a single burst.

During fictive calling elicited by serotonin, instantaneous spike rate was measured as the reciprocal of each spike interval. For each spike, we found the nearest CAP and used this to measure spike-to-CAP time. The nearest CAP to each spike is designated as its "associated CAP." For each associated CAP, we measured the reciprocal of the interval to the following CAP to calculate the instantaneous CAP rate. Fast trill onset was determined as described previously (Barkan et al., 2017). Briefly, when two successive CAPs achieved an instantaneous rate of $>50 \mathrm{~Hz}$, the time of the first CAP was defined as fast trill onset. Fast trill offset was measured using the last CAP before the rate fell $<50 \mathrm{~Hz}$. Some premotor vocal neurons displayed long-lasting depolarizations. Signals were lowpass filtered (X. laevis: $10 \mathrm{~Hz}, X$. petersii: $20 \mathrm{~Hz}$ ), and the "findpeaks" function in the MATLAB Signal Processing Toolbox was used to determine peak time by measuring local maxima. Depolarization duration was defined as peak width at half-height and period was measured from the peak of one depolarization to the peak of the subsequent depolarization. The following measurements were taken from all $\mathrm{PB}_{\mathrm{X}}$ neurons that spiked in association with fictive calls: maximum depolarization during fast trill (Fig. 2A), time between first spike and fast trill onset (Fig. 2B), percentage of spikes associated with a fast trill CAP (Fig. 2C), percentage of spikes that precede the associated CAP (Fig. $2 D$ ), and spike-to-CAP time (Fig. 2E). The data were analyzed using principal component analysis (PCA) and Ward's hierarchical clustering. NMDA-induced membrane oscillations after TTX treatment were analyzed in any $\mathrm{PB}_{\mathrm{X}}$ neuron in which activity accompanied a minimum of one fictive call. NMDA oscillations were analyzed using the same methods as long-lasting depolarizations (see above).

Significance testing. If data were normally distributed with equal variance, linear models (LMs) were used to test the effect of cell type and species for each measurement. If data were not normally distributed and the variance was proportional to the mean, a generalized linear model (GLM) with a gamma distribution and inverse linker function was used. All statistical tests were completed in R (R Core Team, Vienna, Austria). Data are reported in the text as mean $\pm \mathrm{SD}$.

\section{Results}

\section{Identifying premotor vocal neurons in $X$. petersii}

$\mathrm{PB}_{\mathrm{X}}$ neurons form monosynaptic, glutamatergic synapses onto $X$. laevis vocal motor neurons (Wetzel et al., 1985; Zornik and Kelley, 2007, 2008). A recent study (Barkan et al., 2017) provided evidence that $\mathrm{PB}_{\mathrm{X}}$ controls species-specific call duration and period in both $X$. laevis and $X$. petersii. Earlier work in $X$. laevis (Zornik and Yamaguchi, 2012) identified specific premotor vocal neurons in $\mathrm{PB}_{\mathrm{X}}$ that were active during fictive fast trill. To identify potential $X$. petersii homologs of premotor vocal neurons, we recorded in $\mathrm{PB}_{\mathrm{X}}$ using whole-cell patch clamp (Fig. $1 A$ ) from fictively calling $X$. laevis and $X$. petersii brains (Fig. $1 B, C$, Nerve). We recorded $23 X$. laevis premotor vocal neurons in 23 brains and $23 X$. petersii premotor vocal neurons in 23 brains (Fig. $1 B, C$, Neuron). As shown previously in $X$. laevis, these premotor neurons in $\mathrm{PB}_{\mathrm{X}}$ tend to depolarize and spike in close association with fast trills (Fig. $1 B$ ). Here, we identified a population of $\mathrm{PB}_{\mathrm{X}}$ neurons in $X$. petersii with a similar pattern of activity: depolarizations and spikes corresponding to fictive fast trills (Fig. 1C). These recordings suggest that functionally conserved populations of $\mathrm{PB}_{\mathrm{X}}$ neurons underlie fast trill production in both $X$. laevis and $X$. petersii.

\section{$\mathrm{PB}_{\mathrm{X}}$ vocal neurons form two distinct functional groups}

The precise temporal relationships between premotor neurons and nerve activity varied considerably across cells. To assess the heterogeneity between premotor neuron activity and vocal motor output within and between species, we quantified five features that describe the relations between cellular activity and nerve activity during fictive calling: (1) the maximum depolarization of the cell during fast trill, (2) the time difference between the fast trill onset and the first spike in each burst of premotor firing, (3) the percentage of spikes that occurred during fast trill (as opposed to shortly before or after fast trill), (4) the percentage of spikes that preceded the nearest CAP, and (5) the time difference between each spike and the nearest CAP (Fig. 2A-E).

We used these functional characters to perform Ward's hierarchical clustering (Fig. $2 F$ ), which revealed two distinct subgroups of $\mathrm{PB}_{\mathrm{X}}$ neurons in both species. Spiking of neurons in the two subgroups was distinct with respect to timing relative to 
A

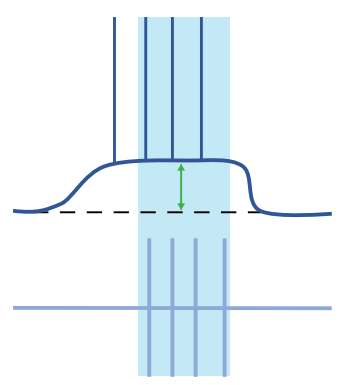

B

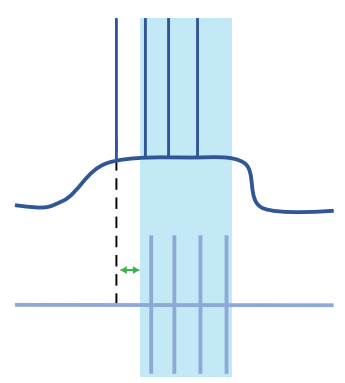

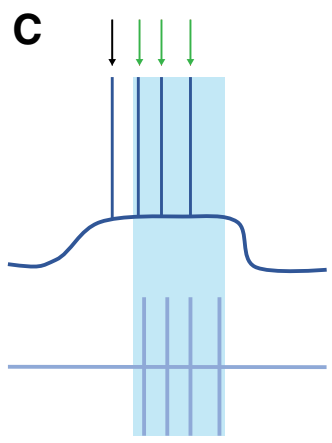

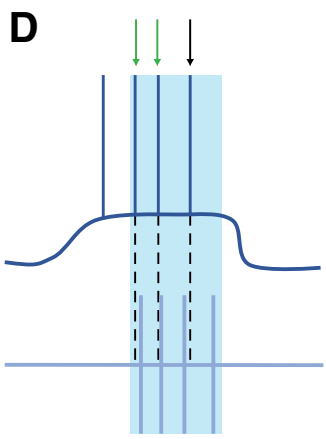

E

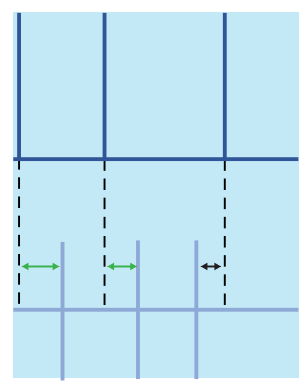

$\mathbf{F}$

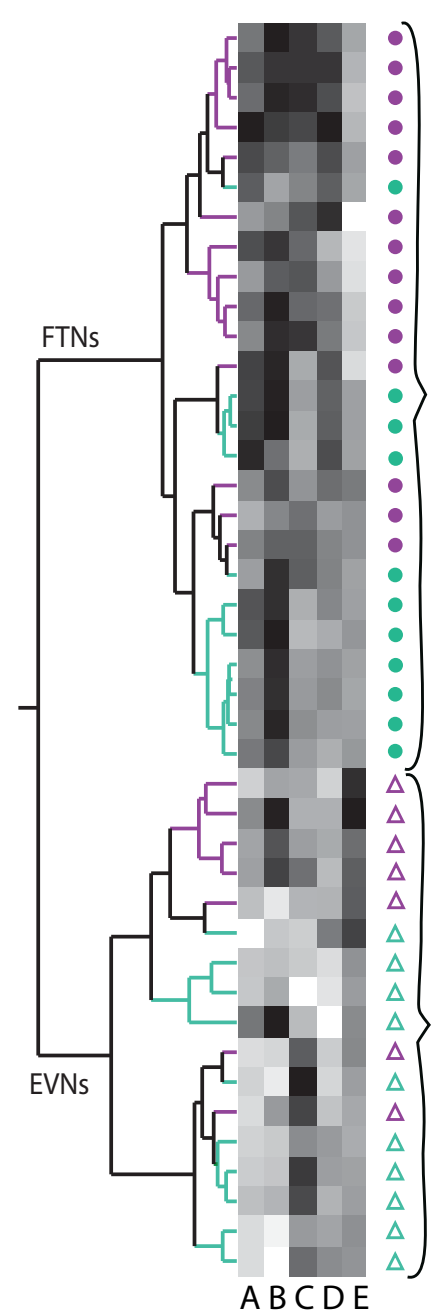

G
$X$. laevis
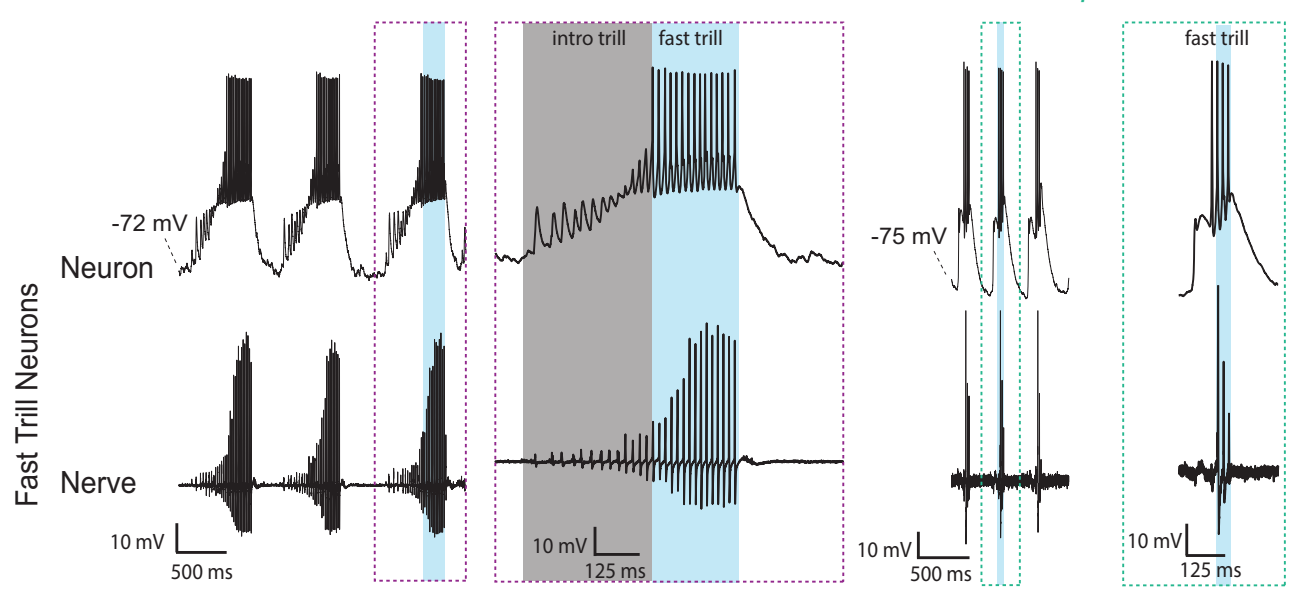

X. petersii
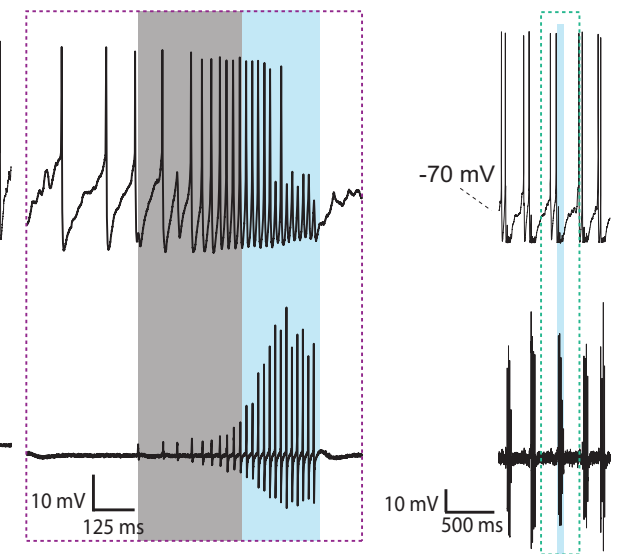

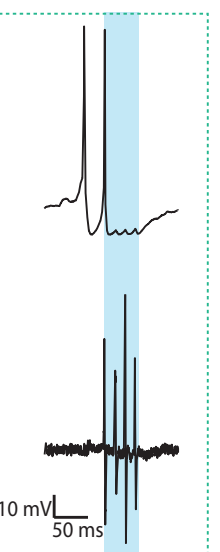

$X$. laevis FTN $\bigcirc$. petersii FTN

$\Delta x$. laevis EVN $\Delta x$. petersii EVN

Figure 2. Two populations of premotor vocal cells in $\mathrm{PB}_{\mathrm{x}} \cdot \boldsymbol{A}-\boldsymbol{E}$, Schematics representing temporal characteristics of premotor vocal neuron activity (top traces, dark blue lines) relative to fictive fast trill (bottom traces, light blue lines) included in Ward's hierarchical clustering and PCA: the maximum depolarization during fast trill ( $\boldsymbol{A}$, arrow), the time between fast trill onset and the first spike in each burst of premotor firing ( $\boldsymbol{B}$, arrow), the percentage of spikes during fast trill ( $\boldsymbol{C}$, green arrows) as opposed to shortly before or after fast trill ( $\boldsymbol{C}$, black arrow), the percentage of spikes that preceded the nearest CAP ( $\boldsymbol{D}$, green arrows), and the times between each spike peak and the nearest CAP peak (positive times: $\boldsymbol{E}$, green arrows; negative times: black arrow). $\boldsymbol{F}$, Ward's hierarchical clustering separates cells into two populations in both species. G, FTNs tend to spike during fast trill (blue box), whereas EVNs tend to begin spiking before fast trill onset; in X. Iaevis, this occurs during introductory trill (gray box). Dashed boxes depict temporally expanded recordings of single calls for each cell type. 


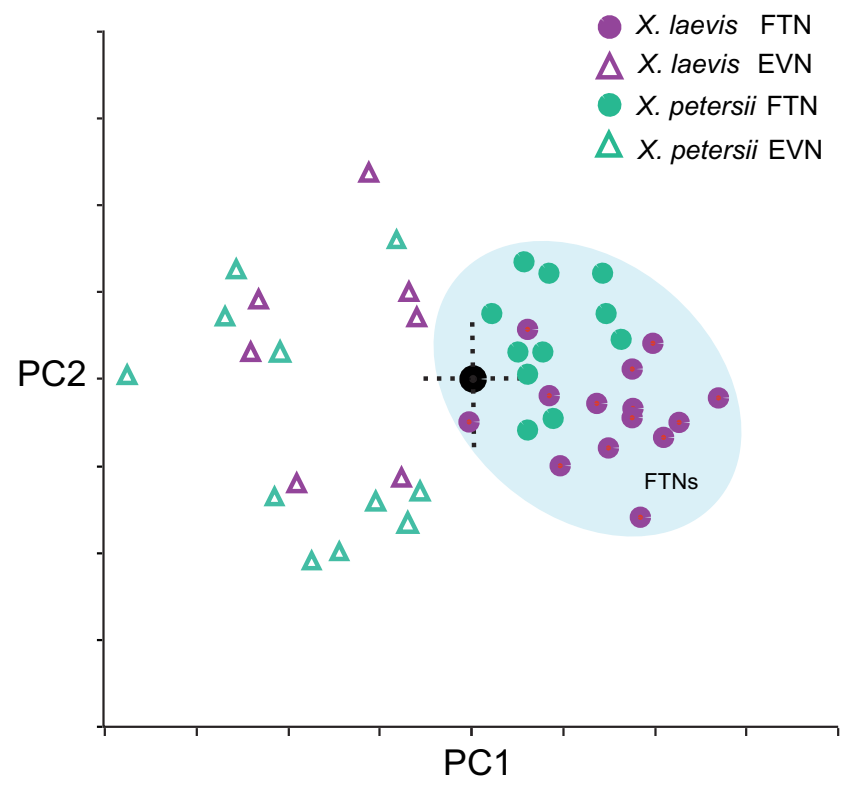

Figure 3. $P C A$ also separates $\mathrm{PB}_{x}$ neurons into two groups: $\mathrm{FTN}$ and EVNs. $\mathrm{PC} 1$ accounts for $52.5 \%$ of the variability, whereas $P(2$ accounts for $21.1 \%$. FTNs (shaded in blue) are more tightly clustered than EVNs. The two cell types overlap along PC2 but not along PC1.

fictive fast trills (Fig. 2G). Neurons in the first subgroup (Fig. 2G, top) began spiking at, or shortly after, the onset of each fast trill, whereas neurons in the second subgroup (Fig. 2B, bottom) were more likely to start firing before the onset of fast trills. In previous studies, all neurons that spiked during fast trill (regardless of precise spike timing or whether they also spiked before fast trills) were termed fast trill neurons (FTNs) (Zornik and Yamaguchi, 2012; Lawton et al., 2017). Here, however, we refine the term FTNs and apply it only to those neurons that cluster with the first group revealed by the hierarchical clustering analyses. We apply a new descriptor, early vocal neurons (EVNs), to the second group of neurons.

PCA of the same measurements corroborate findings from clustering analyses (Fig. 3). The first principal component (PC1) accounted for $52.5 \%$ of the variance in the dataset, with separation of the two cell types along this axis; FTNs were clustered in the positive range of $\mathrm{PC} 1$ and EVNs were found exclusively in the negative range. Principal component 2 (PC2) accounted for $21.1 \%$ of the variance in the dataset, but did not further distinguish FTNs and EVNs. The PC1/PC2 biplot shows that FTNs form a tight cluster, whereas EVNs are more broadly distributed. Together, the hierarchical clustering and PCA suggest that neurons in the vocal premotor nucleus $\mathrm{PB}_{\mathrm{X}}$ of both $X$. laevis and $X$. petersii include two distinct functional cell types, FTNs and EVNs.

Spike-to-CAP timing varies between cell type but not species Which functional features differ between FTNs and EVNs? We first compared the temporal relationships between spikes and nerve CAPs for FTNs and EVNs. FTNs in both species spike during fast trill (Fig. 4A. blue box) and these spikes almost always precede the associated CAP. In contrast, EVN spikes that occur during fast trills are more likely to coincide with or follow the associated nerve CAP (Fig. 4B, blue box). Therefore, the percentage of spikes that precede the associated CAP is greater in FTNs than EVNs [Fig. $4 C$, X. laevis: FTNs $(n=14) 82.1 \pm 13.2 \%$; EVNs $(n=7), 41.7 \pm 24.5 ; X$. petersii: FTNs $(n=11), 90.1 \pm 12.7$; EVNs $(n=11), 34.3 \pm 24.6$; LM: $F_{(2,40)}=22.32, p<0.0001$ for all FTN vs EVN comparisons]. Similarly, the mean time between a premotor spike and the nearest CAP is significantly greater in FTNs $(\sim 4 \mathrm{~ms})$ than in EVNs $(\sim 0 \mathrm{~ms})$ [Fig. $4 D$, X. laevis: FTNs $(n=14)$ $3.6 \pm 1.4 \mathrm{~ms}$; EVNs $(n=7), 0.68 \pm 1.4 ; X$. petersii: $\operatorname{FTNs}(n=11)$, $4.0 \pm 1.3 ; \operatorname{EVNs}(n=11),-0.03 \pm 1.5 ; \mathrm{LM}: F_{(2,40)}=32.4, p<$ 0.0001 for all FTN vs EVN comparisons]. These differences in spike timing between FTNs and EVNs indicate distinct roles for each cell type in vocal rhythm generation.

In X. laevis, fast trills are preceded by "introductory trills" that consist of slow CAP rates $(\sim 20-40 \mathrm{~Hz})$ in contrast to the CAP rates of fast trills $(>50 \mathrm{~Hz}$ ) (Zornik et al., 2010; see Fig. $4 A$, gray boxes vs blue boxes). FTNs usually do not fire action potentials during introductory trills (Fig. $4 A$, gray boxes), whereas EVNs do (Fig. $4 B$, gray boxes). Unlike their spikes during fast trills, which coincide with or follow CAPs (Fig. 4B, blue boxes), EVN spikes during introductory trills are more likely to precede CAPs (Fig. $4 B$, gray boxes). In $X$. petersii, fictive fast trills are brief and are not preceded by a series of slower introductory CAPs (Fig. 4). Although X. petersii EVNs often spike before the onset of fictive fast trills, spikes are not accompanied by nerve CAPs as in X. laevis (Fig. 4B).

Spike timing differences in FTNs and EVNs support the possibility of distinct roles for each cell type. The lack of cell type differences between $X$. laevis and $X$. petersii suggests that each subtype plays a similar role in regulating spike timing across species.

\section{$\mathrm{PB}_{\mathrm{X}}$ neuron depolarizations differ between cell type and species}

Many $\mathrm{PB}_{\mathrm{X}}$ neurons in $X$. laevis produce long-lasting depolarizations that coincide with fictive fast trills (Zornik and Yamaguchi, 2012; see representative examples in Fig. 5A). Do these depolarizations vary between cell type or species? Although all FTNs produced long-lasting depolarizations during fictive fast trills, only $50 \%$ of $X$. laevis and $42 \%$ of $X$. petersii EVNs exhibited long-lasting depolarizations of $>1 \mathrm{mV}$ during fictive fast trills (Fig. 5B, EVNs with longlasting depolarizations; Fig. 2G, EVNs without long-lasting depolarizations during fast trill). Depolarization amplitude is significantly greater in FTNs compared with EVNs in both species (Fig. $5 C$, X. laevis: FTNs $(n=14), 22.5 \pm 8.3 \mathrm{mV}$; EVNs $(n=7)$, = $3.7 \pm 3.6 ; X$. petersii: FTNs $(n=11), 17.4 \pm 7.1$; EVNs $(n=11)$, $4.0 \pm 10.3$; LM: $F_{(2,40)}=21.6, p<0.0001$ for all FTN vs EVN comparisons). However, an effect of species on depolarization amplitude was not observed (LM: $p>0.05$ ). Therefore, depolarization amplitudes vary between cell type but not species.

Although depolarization amplitude varies across cell type but not species, the duration and period of depolarizations vary across species but not cell type. X. laevis FTN and EVN depolarization durations are significantly greater than those of $X$. petersii FTNs and EVNs [Fig. 5D, X. laevis: FTNs $(n=14), 514.4 \pm 99.7$ ms; EVNs $(n=4),=852.8 \pm 130.6 ; X$. petersii: FTNs $(n=11)$, $121.1 \pm 33.9$; EVNs $(n=5), 133.3 \pm 53.1$; GLM (gamma) residual deviance $=2.1$ on $31 \mathrm{df}, p<0.0001$ for all FTN vs EVN comparisons]. The periods of $X$. laevis FTN and EVN depolarizations are also significantly longer than those in X. petersii [Fig. 5E, $X$. laevis: FTNs $(n=14), 1244.8 \pm 304.1 \mathrm{~ms}$; EVNs $(n=4),=$ $1218.6 \pm 179.5$; X. petersii: FTNs $(n=11), 367.4 \pm 126.2$; EVNs $(n=5), 345.8 \pm 126.0$; GLM (gamma) residual deviance $=2.1$ on $31 \mathrm{df}, p<0.0001$ for all FTN vs EVN comparisons].

In $X$. laevis EVNs that produced long-lasting depolarizations, neurons remained depolarized throughout both introductory and fast trills, leading to prolonged depolarization durations compared to FTNs (see Fig. 5B, X. laevis for a representative example of prolongation). Therefore, depolarizing $X$. laevis EVNs exhibited the longest duration of any depolarizing $\mathrm{PB}_{\mathrm{X}}$ neuron 
A

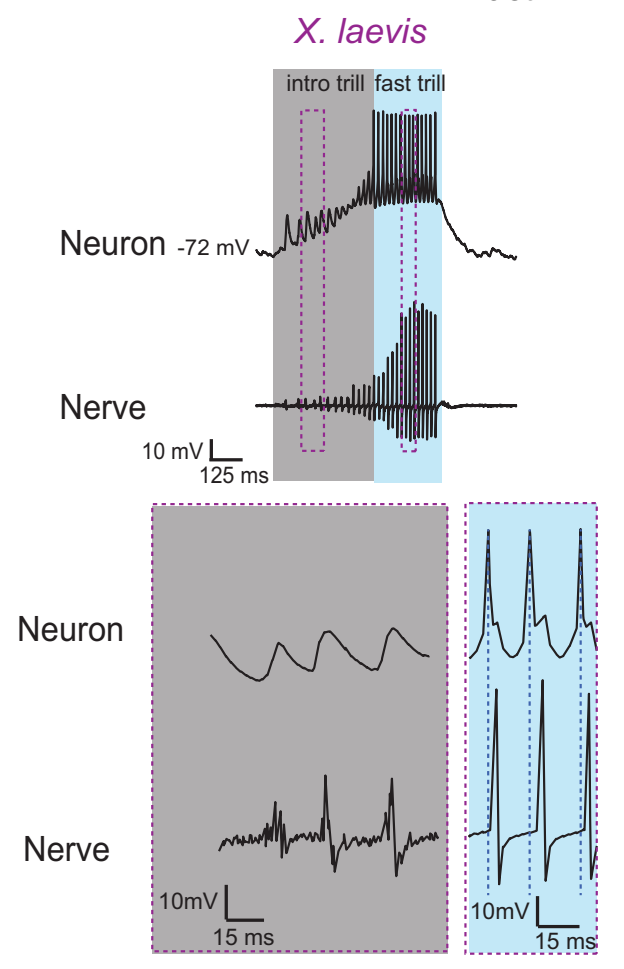

C
B

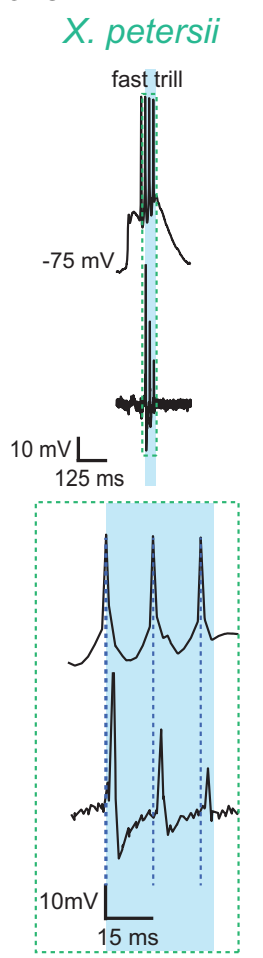

Early Vocal Neurons
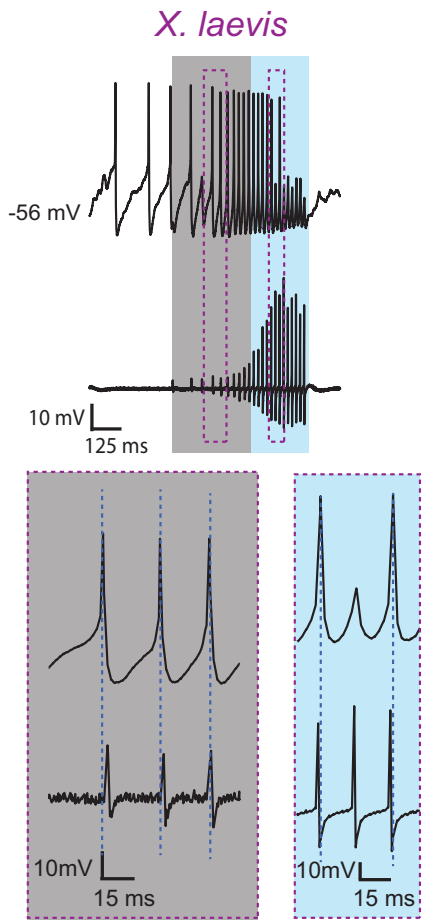
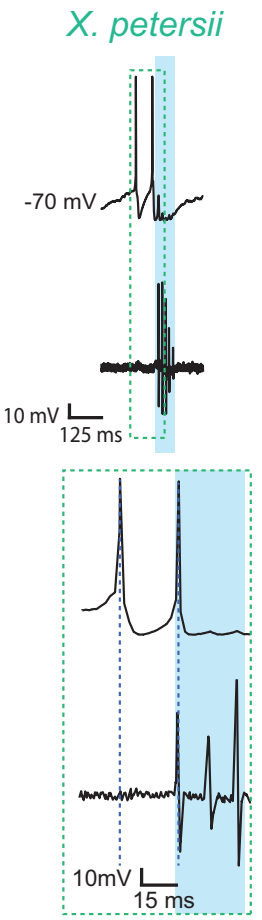

D

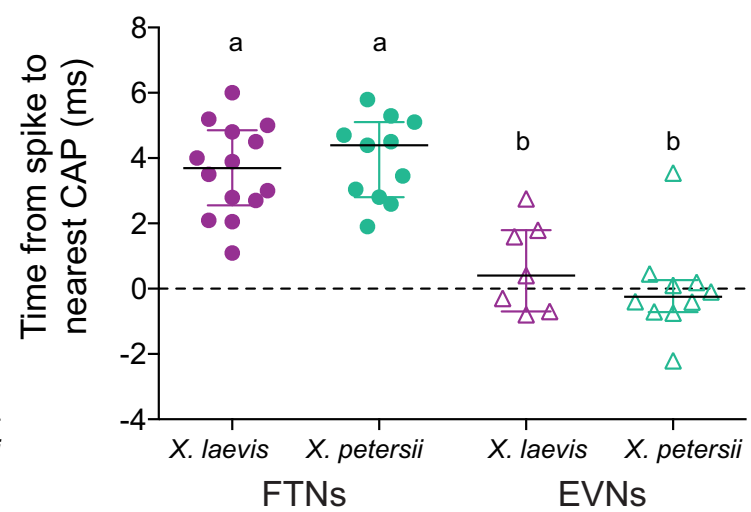

Figure 4. FTN spikes precede CAPs during fast trill, but EVN spikes occur during or after CAPs. A, Representative examples of X. laevis (right) and X. petersii (left) FTN activity during fictive fast trill (blue box) and introductory trill (gray box; $X$. laevis only). Temporally expanded traces of individual spikes and corresponding CAPs are depicted in dashed boxes in bottom panel. Spikes are demarcated by blue dashed lines. In both species, FTN spikes occur during fictive fast trill and spikes precede CAPs. $B$, Representative examples of $X$. laevis (right) and X. petersii (left) EVN activity during fictive fast trill (blue box) and introductory trill (gray box; X. laevis only). Temporally expanded traces of individual spikes and corresponding CAPs are depicted in dashed boxes in the bottom panels. EVN spikes occur before fast trill onset and precede nerve CAPs during introductory trill. During fast trill, EVN spikes follow or coincide with associated nerve CAPs. EVNs cease spiking before fast trill offset. C, In FTNs (closed circles) the percentage of spikes that precede CAPs during fast trill is significantly higher than in EVNs (open triangles) for $X$. laevis [purple; FTNs ( $n=14$ ) $82.1 \pm$ 13.2\%; $\operatorname{EVNs}(n=7), 41.7 \pm 24.5)$ and X. petersii (green; FTNs $(n=11), 90.1 \pm 12.7$; EVNs $(n=11)$; LM: $p<0.0001$ for all FTN vs EVN comparisons]. There is no effect of species $(p>0.05)$. In this and subsequent figures, data labeled with different lowercase letters are significantly different, black horizontal lines represent median values, and whiskers represent interquartile range. $\boldsymbol{D}$, Spike to nearest CAP time is significantly more positive in FTNs ( $\sim 4 \mathrm{~ms})$ than EVNs ( $\sim 0 \mathrm{~ms})[X$. Iaevis: FTNs $(n=14) 3.6 \pm 1.4 \mathrm{~ms}$; $\operatorname{EVNs}(n=7), 0.68 \pm 1.4 ; X$. petersii: FTNs $(n=11), 4.0 \pm 1.3$; $\operatorname{EVNs}(n=11),-0.03 \pm 1.5 ; \mathrm{LM}: p<0.0001$ for all FTN vs EVN comparisons]. There is no effect of species $(p>0.05)$.

$(p<0.0001$; Fig. 5D). X. petersii FTN and EVN depolarizations did not differ significantly in duration $(p>0.05)$, probably because $X$. petersii fast trills are not preceded by introductory trills. Therefore, FTNs may control fast trill, whereas EVNs in $X$. laevis may control introductory trill.

In summary, depolarization amplitudes vary between cell type, whereas durations and periods vary across species. Differences in long-lasting depolarization durations suggest that both FTNs and
EVNs may be capable of controlling species-specific fast trill duration and period.

\section{Identifying species-specific membrane properties}

Species-specific differences in FTN and EVN depolarization duration and period may be due to intrinsic cellular properties or they may depend on distinct patterns of network connections. To determine whether intrinsic membrane properties contribute to 
A
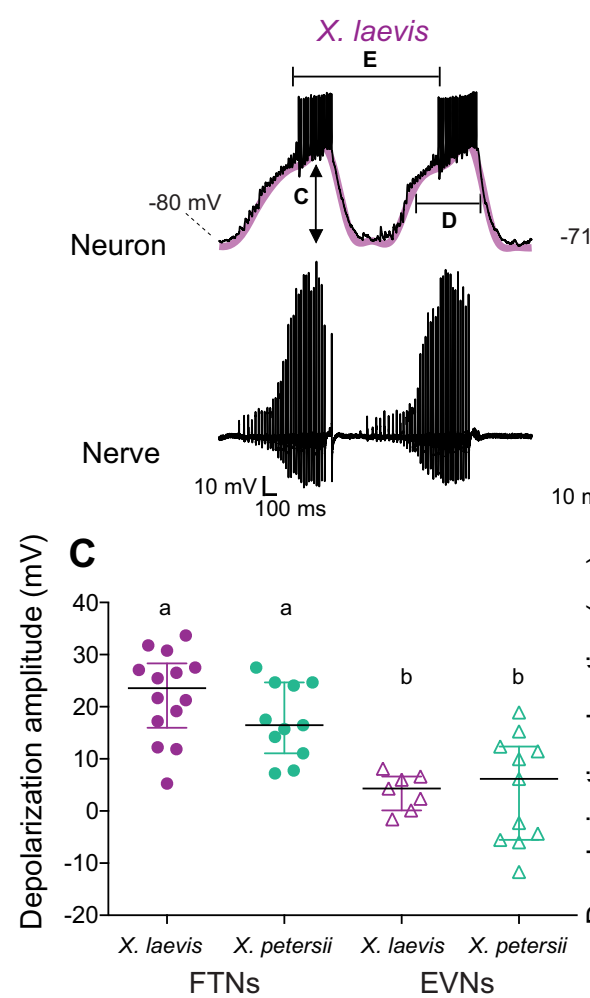

Figure 5. $\quad \mathrm{PB}_{X}$ neuron depolarizations differ across cell type and species. $A$, Representative recordings of $\mathrm{FTN}$, which all produced long-lasting depolarizations [purple in $X$. laevis (10 Hz low-pass filter), green in X. petersii (20 Hz low-pass filter)] coinciding with fictive fast trill. $B$, Representative recordings of EVNs, in which only $50 \%$ (X. laevis) or $42 \%$ (X. petersii) of cells produced long-lasting depolarizations. EVNs that produced a long-lasting depolarization are illustrated. For examples of EVNs without an associated long-lasting depolarization, see Figures $2 G$ (bottom) and $4 B$. C, Depolarization amplitude (" $C$ " in Fig. 5A) is significantly higher ( $L M: p<0.0001$ ) in FTNs (X. laevis $n=14, X$. petersii $n=11$ ) than EVNs (X. laevis $n=7, X$. petersii $n=11)$ for all FTN versus EVN comparisons; there is no effect of species ( $p>0.05$ ). $D$, Depolarization duration (" $\mathrm{D}$ " in Fig. $5 A$ ) is significantly longer in $X$. laevis $\mathrm{PB}_{\mathrm{x}}$ neurons than $X$. petersii $\mathrm{PB} \times \mathrm{x}$ neurons (GLM: $p<0.0001$ for all comparisons). In $X$. laevis EVNs that exhibited depolarizations $(n=4)$, durations were significantly longer than $X$. laevis FTN depolarizations $(n=14 ; p<0.001)$. Depolarization duration did not

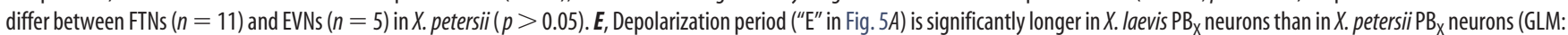
$p<0.0001$ for all comparisons). FTN and EVN depolarization periods did not differ between species ( $p>0.05$ ).

species-typical depolarizations, we compared spike responses of $\mathrm{PB}_{\mathrm{X}}$ neurons during depolarizing current steps across species and cell type (Fig. $6 A, C$ ). We found that there were differences in the duration of spike bursts induced by current steps. Although overall spike rate was similar between species and cell type $[X$. laevis: FTNs $(n=8), 124.7 \pm 63.1 \mathrm{~Hz}$; EVNs $(n=8), 63.5 \pm 37.2 ; X$. petersii: FTNs $(n=9), 89.6 \pm 49.9$; EVNs $(n=7), 85.5 \pm 58.3$; LM, $F_{(2,39)}=1.8, p>0.05$ for all comparisons; data not shown], FTN spike bursts in $X$. laevis were significantly longer than in $X$. petersii at medium and high current levels [Fig. 6B, medium: $>110-150 \%$ rheobase; $X$. laevis FTNs $(n=11): 559.9 \pm 738.8$ $\mathrm{ms} ; X$. petersii FTNs $(n=9): 64.0 \pm 31.7 ;$ GLM (gamma) residual deviance $=40.2$ on $32 \mathrm{df}, p \leq 0.01$; high: $>150-200 \%$ rheobase; $X$. laevis FTNs $(n=8): 898.0 \pm 782.2 \mathrm{~ms} ; X$. petersii FTNs $(n=7)$ : $56.2 \pm 29.8 \mathrm{GLM}$ (gamma) residual deviance $=23.4$ on $26 \mathrm{df}, p \leq$ 0.006 ]. EVN burst durations did not differ by species [Fig. $6 D$, medium current: $X$. laevis EVNs $(n=7): 1643.4 \pm 545.7 ; X$. petersii EVNs $(n=9), 721.4 \pm 853.4$; GLM (gamma) residual deviance $=$ 2.1 on $31 \mathrm{df}, p>0.05)$; high current: $X$. laevis $\mathrm{EVNs}(n=8)$ : $1260.6 \pm 733.0$; X. petersii EVNs $(n=7), 690.5 \pm 823.3$; GLM (gamma) residual deviance $=23.4$ on $26 \mathrm{df} p>0.05$ ]. These results suggest that voltage-dependent membrane currents in FTNs, but not EVNs, vary between species.

We compared passive membrane properties across species and cell type. We found no differences across cell type or species in input resistance (Fig. 6E), resting membrane potential (Fig.
$6 F$ ), and capacitance (Fig. $6 G$ ) [resistance: X. laevis: FTNs $(n=$ 14), $240.3 \pm 149.0 \mathrm{MOhm}$; EVNs $(n=8), 278.6 \pm 162.6 ; X$. petersii: FTNs $(n=11), 200.3 \pm 58.1$; EVNs $(n=12), 229.2 \pm$ 97.6; GLM (gamma): residual deviance $=8.4$ on $41 \mathrm{df}, p>0.05$ for all comparisons; resting membrane potential: X. laevis: FTNs $(n=14),-74.2 \pm 5.6 \mathrm{mV}$; EVNs $(n=8),-68.3 \pm 4.2 ; X$. petersii: FTNs $(n=11),-68.2 \pm 5.0$; EVNs $(n=12),-69.8 \pm$ 3.5; LM, $F_{(2,42)}=3.1, p>0.05$ for all comparisons; capacitance: X. laevis: FTNs $(n=9), 305.8 \pm 130.1 \mathrm{pF} ; \mathrm{EVNs}(n=3), 480.1 \pm$ 256.4; X. petersii: FTNs $(n=6), 286.3 \pm 125.4$; EVNs $(n=7)$, $334.4 \pm 149.4 ; \mathrm{LM}, F_{(2,22)}=1.4, p>0.05$ for all comparisons]. Therefore, these passive properties do not appear to account for functional differences.

To assess whether hyperpolarization-activated current $\left(I_{\mathrm{h}}\right)$ contributes to functional differences, we measured the sag index, in which a value $>0.1$ indicates significant $I_{\mathrm{h}}$ current is present (Farries et al., 2005). We found no differences across species or cell type in sag index [Fig. $6 H$, X. laevis: FTNs $(n=15), 0.094 \pm$ 0.051 ; EVNs $(n=8), 0.143 \pm 0.142 ; X$. petersii: FTNs $(n=11)$, $0.096 \pm 0.051 ; \mathrm{EVNs}(n=12), 0.134 \pm 0.066 ; \mathrm{LM}, F_{(2,42)}=1.7$, $p>0.05$ for all comparisons]. Therefore, sag potentials are common to all $\mathrm{PB}_{\mathrm{X}}$ premotor vocal neurons, but do not appear to account for differences between cell type or species. Further, there was no difference in rheobase (Fig. 6I) or action potential half-width (Fig. $6 J$ ) [rheobase: X. laevis: FTNs $(n=13), 680.8 \pm 467.8$ pA; EVNs $(n=8), 363.8 \pm 178.3 ; X$. petersii: FTNs $(n=10), 463.2 \pm$ 
Fast Trill Neurons

A

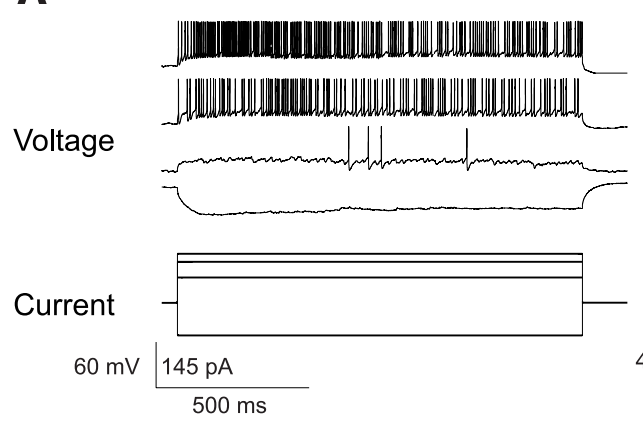

X. petersii

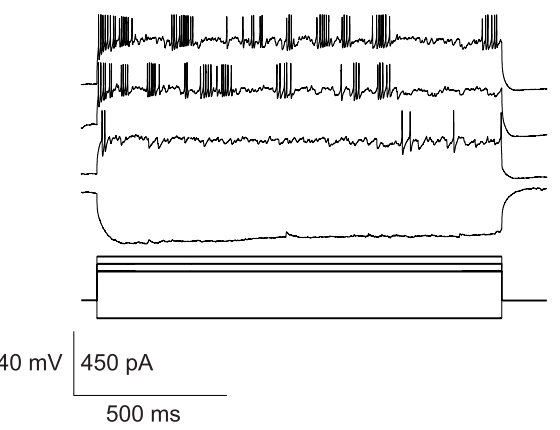

B

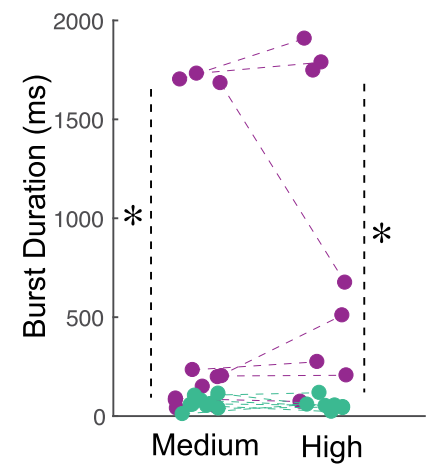

D

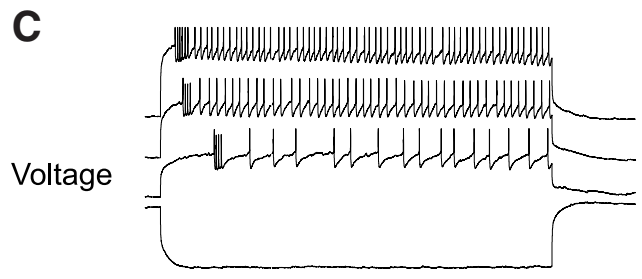

Early Vocal Neurons

\section{Current}

$65 \mathrm{mV} \frac{700 \mathrm{pA}}{500 \mathrm{~ms}}$
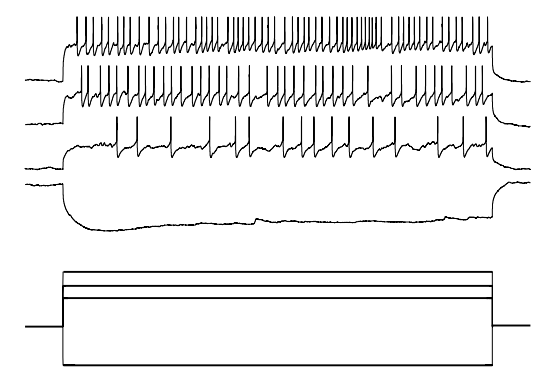

$70 \mathrm{mV} \frac{350 \mathrm{pA}}{500 \mathrm{~ms}}$

$\triangle$ X. laevis EVN $\triangle$ X. petersii EVN

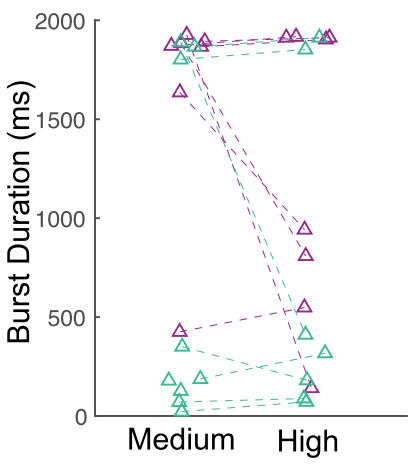

E

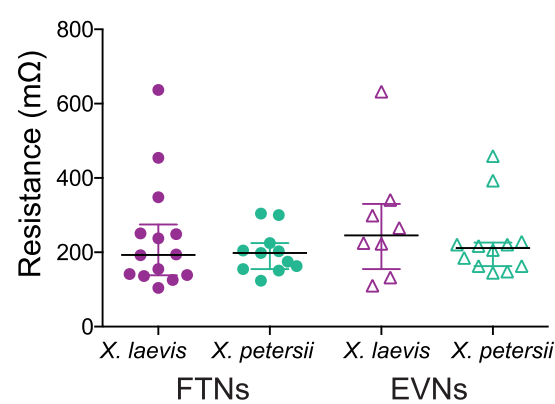

H

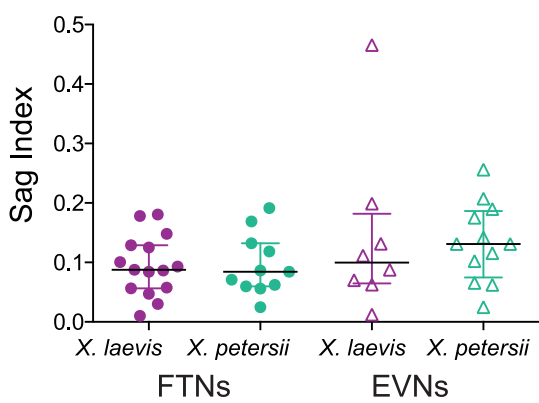

F

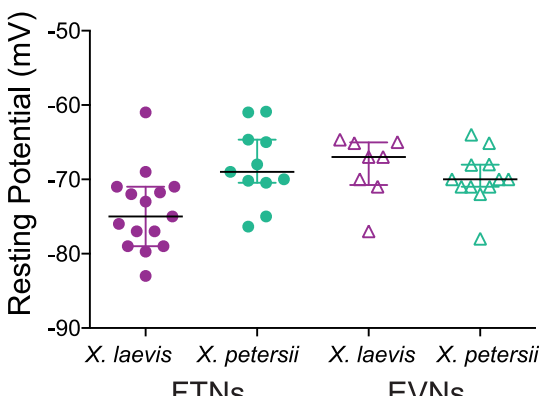

FTNs

I

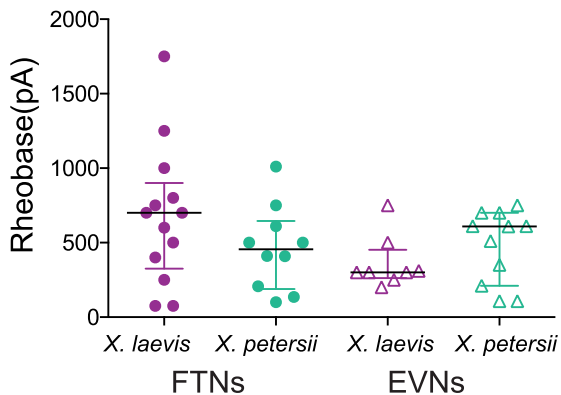

G

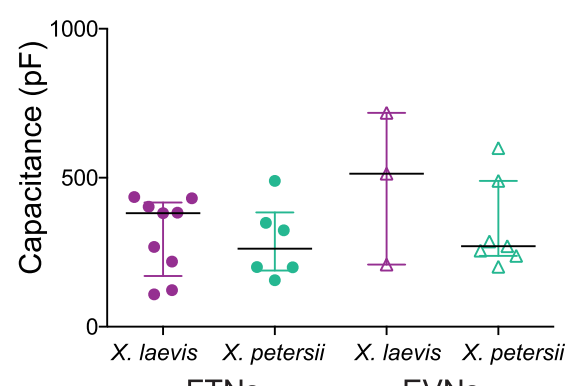

FTNs

EVNs

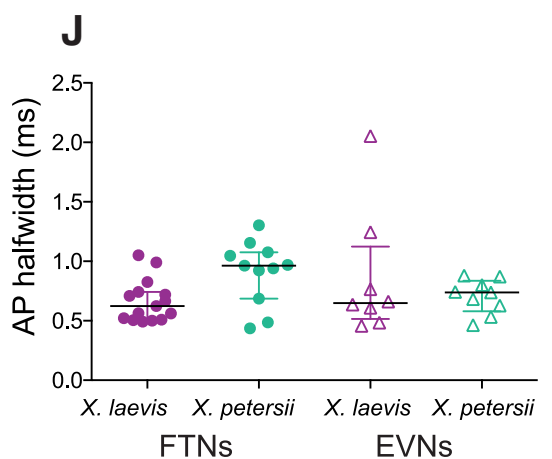

Figure 6. Current injections reveal that FTN spike burst durations, but not other intrinsic properties, differ between species. $A$, Representative FTN responses to current steps in $X$. laevis (left) and $X$. petersii (right). Four current steps are shown: the most extreme negative step, rheobase, medium current levels ( $>110-150 \%$ rheobase) and high current levels ( $>150-200 \%$ rheobase). $B$, Burst duration of $X$. petersii FTNs is significantly shorter than $X$. laevis FTNs at medium and high current steps [medium: $>110-150 \%$ rheobase; $X$. laevis FTNs $(n=11): 559.9 \pm 738.8 \mathrm{~ms} ; X$. petersii FTN $(n=9): 64.0 \pm 31.7 ;$ GLM: $p<0.01$ for all species comparisons; high: $>150-200 \%$ rheobase; X. laevis FTNs $(n=8): 898.0 \pm 782.2$ ms; $X$. petersii FTNs $(n=7): 56.2 \pm 29.8 ; G L M$ : $p \leq 0.006$ ]. Asterisks $\left(^{*}\right)$ indicate statistically significant difference between species. C, Representative EVN responses to current steps in X. laevis and X. petersii EVNs. (Figure legend continues.) 
282.1; EVNs $(n=11), 478.6 \pm 242.4$; GLM (gamma): residual deviance $=4387356$ on $38 \mathrm{df}, p>0.05$ for all comparisons; action potential half-width: $X$. laevis: FTNs $(n=15), 0.67 \pm 0.18 \mathrm{~ms}$; EVNs $(n=8), 0.86 \pm 0.54 ; X$. petersii: FTNs $(n=11), 0.91 \pm 0.27$; EVNs $(n=9), 0.70 \pm 0.14 ; \mathrm{LM}, F_{(2,39)}=1.3, p>0.05$ for all comparisons].

In summary, of all of the intrinsic properties measured during current injections, only spike burst duration in FTNs varied between species; no intrinsic features differed between cell type. FTNs respond to current steps with burst durations consistent with their call durations: $X$. laevis FTNs produce long bursts, whereas $X$. petersii FTNs produce short bursts. This supports the possibility that intrinsic FTN differences encode behavioral differences across species.

\section{NMDA-responsive currents may underlie species-specific vocal patterns}

To further address the possibility that intrinsic FTN properties may underlie vocal differences between species, we synaptically isolated $\mathrm{PB}_{\mathrm{X}}$ neurons with $0.5 \mu \mathrm{M}$ TTX. After TTX treatment, NMDA was applied to induce membrane potential oscillations (as per Zornik and Yamaguchi, 2012). Oscillations were evoked in $5 X$. petersii and $6 X$. laevis FTNs (Fig. 7A, bottom trace) and in $6 X$. petersii and $3 X$. laevis EVNs (Fig. $7 D$, bottom trace). All neurons that were held stably throughout this protocol produced oscillations, allowing us to determine oscillation durations and periods. The duration and period of NMDA-induced oscillations in FTNs differed significantly across species [Fig. 7 B, $C$, duration: $X$. laevis FTNs $(n=7): 375.0 \pm 146.1 \mathrm{~ms} ; X$. petersii FTNs $(n=5)$ : $190.1 \pm 27.5$; GLM (gamma) residual deviance $=3.1$ on $34 \mathrm{df}$, $p<0.0001$; period: X. laevis FTNs: $1179.6 \pm 302.1 \mathrm{~ms}$; X. petersii FTNs: $527.4 \pm 82.6$; GLM (gamma) residual deviance $=3.1$ on $34 \mathrm{df}, p<0.0001]$. Therefore, the longer depolarization duration and period observed for $X$. laevis compared with $X$. petersii during fictive calling (Fig. $5 D, E$ ) is also apparent in NMDA-induced membrane oscillations.

In contrast, whereas EVNs also oscillated, their durations and periods did not differ between species [Fig. $7 E, F$, duration: $X$. laevis EVNs $(n=3): 249.9 \pm 55.3 \mathrm{~ms} ; X$. petersii EVNs $(n=6)$ : $329.1 \pm 312.1$; GLM (gamma) residual deviance $=3.1$ on $34 \mathrm{df}$, $p>0.05$; period: $X$. laevis EVNs $(n=3): 543.1 \pm 42.4 \mathrm{~ms} ; X$.

\section{$\leftarrow$}

(Figure legend continued.) Four current steps are shown: the most extreme negative step, rheobase, medium current levels ( $>110-150 \%$ rheobase), and high current levels ( $>150-200 \%$ rheobase). D, Burst duration of EVNs in X. laevis and X. petersii do not differ across species at medium or high current steps [medium: $X$. laevis EVNs $(n=7): 1643.4 \pm 545.7 \mathrm{~ms} ; X$. petersii EVNs $(n=9), 721.4 \pm 853.4 ; G L M: p>0.05 ;$ high:X. laevis EVNs $(n=8): 1260.6 \pm 733.0 ; X$. petersii EVNs $(n=7), 690.5 \pm 823.3$; GLM $p>0.05$ for all species comparisons]. $\boldsymbol{E}$, Input resistance does not differ across $\mathrm{PB}_{X}$ neuron type or species [X. laevis: FTNs $(n=14), 240.3 \pm$ 149.0 MOhm; EVNs $(n=8), 278.6 \pm 162.6$; X.petersii:FTNs $(n=11), 200.3 \pm 58.1$; EVNs $(n=$ 12), $229.2 \pm 97.6$; GLM: $p>0.05$ for all comparisons]. $\boldsymbol{F}$, Resting potential does not differ across $\mathrm{PB}_{\mathrm{x}}$ neuron type or species [X. laevis: FTNs $(n=14),-74.2 \pm 5.6 \mathrm{mV}$; EVNs $(n=8)$, $-68.3 \pm 4.2 ; X$. petersii:FTNs $(n=11),-68.2 \pm 5.0 ; \mathrm{EVNs}(n=12),-69.8 \pm 3.5 ; \mathrm{LM}: p>$ 0.05 for all comparisons]. $G$, Capacitance does not differ across $\mathrm{PB}_{\mathrm{X}}$ neuron type or species $[X$. laevis: FTNs $(n=9), 305.8 \pm 130.1 \mathrm{pF}$; EVNs $(n=3), 480.1 \pm 256.4 ; X$. petersii: FTNs $(n=6)$, $286.3 \pm 125.4 ;$ EVNs $(n=7), 334.4 \pm 149.4 ;$ LM: $p>0.05$ for all comparisons]. $\boldsymbol{H}$, Sag index does not differ across $\mathrm{PB}_{X}$ neuron type or species [X. laevis: FTNs $(n=15), 0.094 \pm 0.051$; EVNs $(n=8), 0.143 \pm 0.142 ;$ X. petersii: FTNs $(n=11), 0.096 \pm 0.051$; EVNs $(n=12), 0.134 \pm$ 0.066; LM: $p>0.05$ for all comparisons]. $I$, Spike threshold does not differ across $\mathrm{PB}_{\mathrm{X}}$ neuron type or species [X. laevis: FTNs $(n=13), 680.8 \pm 467.8 \mathrm{pA}$; EVNs $(n=8), 363.8 \pm 178.3 ; X$. petersii: FTNs $(n=10), 463.2 \pm 282.1 ; \mathrm{EVNs}(n=11), 478.6 \pm 242.4 ; \mathrm{GLM}: p>0.05$ for all comparisons). FTNs $(n=6), 286.3 \pm 125.4 ;$ EVNs $(n=7), 334.4 \pm 149.4 ; \mathrm{LM} p>0.05$ for all comparisons]. $J$, Action potential half-width does not differ across $\mathrm{PB}_{\mathrm{X}}$ neuron type or species $[X$. laevis: FTNs $(n=15), 0.67 \pm 0.18 \mathrm{~ms}$; EVNs $(n=8), 0.86 \pm 0.54 ; X$. petersii: FTNs $(n=11)$, $0.91 \pm 0.27 ; \mathrm{EVNs}(n=9), 0.70 \pm 0.14 ; \mathrm{LM}: p>0.05$ for all comparisons]. petersii EVNs $(n=6): 878.8 \pm 688.4$; GLM (gamma) residual deviance $=3.1$ on $34 \mathrm{df}, p>0.05$ ]. Therefore, intrinsic membrane properties in FTNs, but not EVNs, are strong candidates for encoding species-specific call features, including duration and period of advertisement calls.

\section{Discussion}

Divergent membrane properties may underlie vocal evolution Behavioral differences between species should reflect differences in neuronal membrane properties and network properties of the responsible neural circuits. Determining precisely which differences are responsible for behavioral variation is key to understanding how neural circuits evolve. To explore this, we used whole-cell recording in isolated brains from two species with distinct vocal patterns, $X$. laevis and $X$. petersii, to identify and characterize hindbrain vocal premotor neurons in the $\mathrm{PB}_{\mathrm{X}}$ that are active during fictive vocalizations.

Our analyses revealed two functionally distinct premotor cell types in both species: EVNs and FTNs. EVN spiking typically precedes fictive fast trill onset, whereas FTNs spike almost exclusively during fictive fast trills. Most EVN and FTN membrane properties did not differ within or across species and both subtypes generated TTX-insensitive, NMDAR-dependent oscillations. However, only FTN oscillations matched their own species' distinct fast trill pattern: $X$. laevis FTN oscillations were long in duration and period, whereas $X$. petersii FTN oscillations were brief in duration and period. We suggest that FTNs code for the duration and period of fast trills and that evolution of FTN membrane properties is an important driver of vocal divergence in $X$. laevis and $X$. petersii.

\section{Neural basis of behavioral divergence: insights from other systems}

The identified links between behavioral differences and membrane properties are few and largely comprise studies of invertebrates. In the crab stomatogastric ganglion, behavioral variation between conspecifics is correlated with differential expression of multiple voltage-gated channels, including channels that produce hyperpolarization-activated inward current $\left(I_{\mathrm{h}}\right)$ and the transient outward current $\left(I_{\mathrm{A}}\right)$ (Goaillard et al., 2009). Animals in that study were wild-caught conspecifics and it is unclear if differences were due to genetic variation, distinct environmental conditions across individuals, or a combination. A recent study of two Drosophila species (D. simulans and D. mauritianus) revealed that courtship song differences between two wild-type isolates reflect altered splicing of a calcium-dependent potassium channel transcript (Ding et al., 2016). This is a rare example of a behavioral difference driven via a known genetic mechanism. The neurons underlying Drosophila courtship behavior differences are thus of great interest but have not yet been reported.

The hindbrain circuit involved in generating male Xenopus calls is more fully described and the $\mathrm{PB}_{\mathrm{X}}$ has been shown to play an essential role in vocal pattern generation (Rhodes et al., 2007; Zornik and Yamaguchi, 2012; Yamaguchi et al., 2017). The identification of intrinsic $\mathrm{PB}_{\mathrm{X}}$ neuron properties that are tied to vocal patterns should facilitate genetic studies and contribute to understanding connections among behaviors, neurons, ion channels, and genetics across taxa.

\section{Candidate mechanisms for neuronal and behavioral evolution}

What membrane properties underlie functional differences between X. laevis and X. petersii FTNs? Because species differences 
A

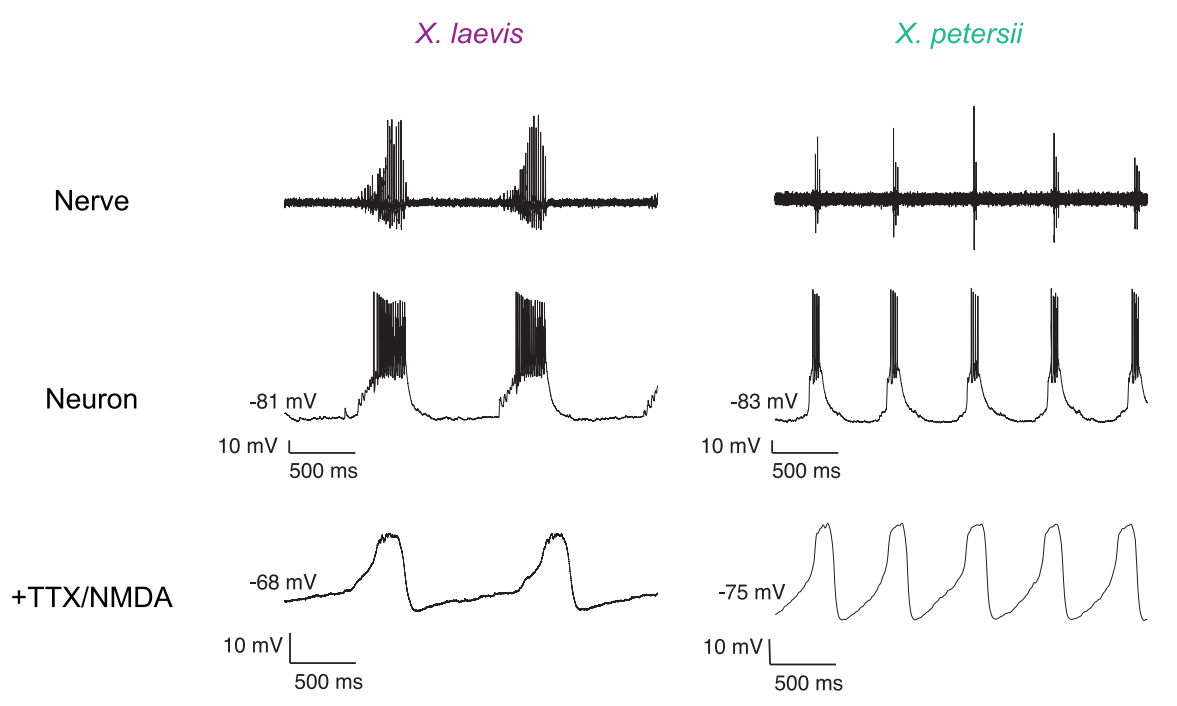

Fast Trill Neurons
B

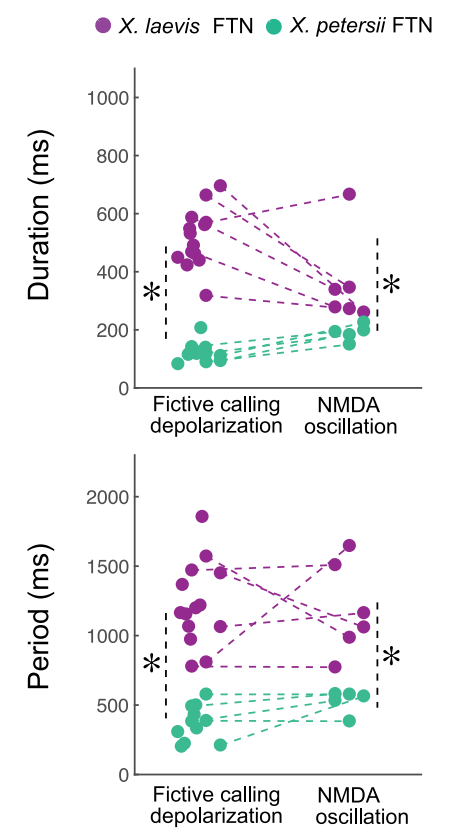

D

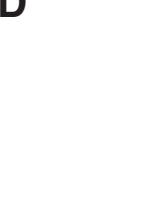

Nerve

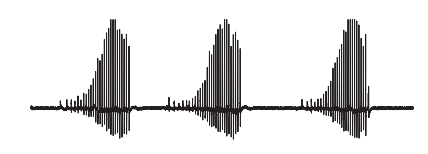

Early Vocal Neurons

X. laevis

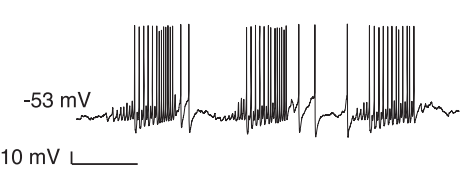

$10 \mathrm{mV} \frac{}{500 \mathrm{~ms}}$

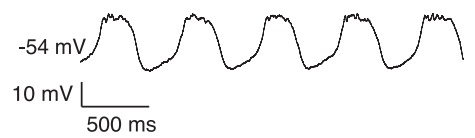

C

E

$\mathbf{F}$

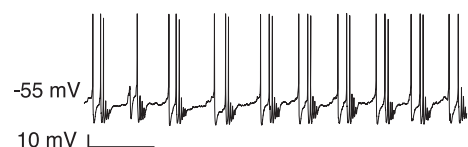

$10 \mathrm{mV} \frac{}{500 \mathrm{~ms}}$

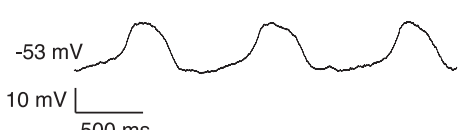

$\triangle X$. laevis EVN $\triangle X$. petersii $\mathrm{EVN}$
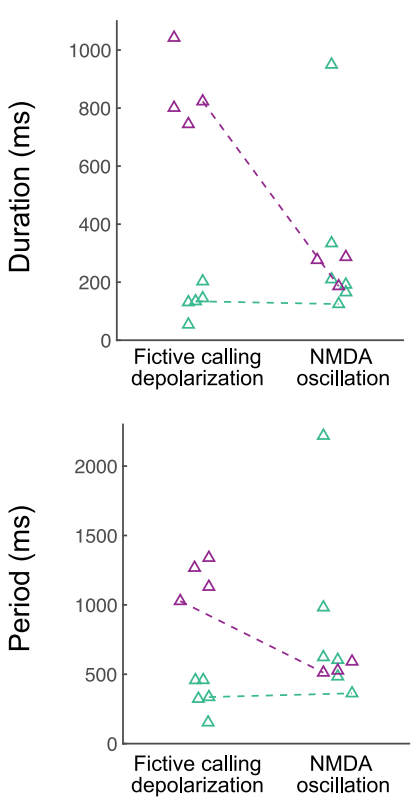

Figure 7. FTNs, but not EVNs, intrinsically encode species-specific call duration and period. $A$, Representative FTN activity (Neuron) in X. laevis and X. petersii during fictive calling (Nerve). All FTNs displayed characteristic long-lasting depolarizations (X. laevis, $n=14 ; X$. petersii, $n=11$; see Fig. 5). Representative oscillations of the same FTN in response to NMDA in the presence of TTX $(+$ TTX/NMDA; X. laevis, $n=7 ; X$. petersii, $n=5)$. B. As observed for long-lasting depolarizations during fictive calling, NMDA-induced oscillation durations were significantly longer in $X$. laevis than in X. petersii (GLM: $p<0.0001$ for all comparisons). Asterisks $\left(^{*}\right)$ indicate statistically significant difference between species. C, As observed for long-lasting depolarizations during fictive calling, the NMDA-induced oscillation periods were significantly longer in X. laevis than in X. petersii (GLM: $p<0.0001$ for all comparisons). Asterisks $\left({ }^{*}\right)$ indicate statistically significant difference between species. D, Representative EVN activity (Neuron) in X. laevis and $X$. petersii during fictive calling (Nerve) and NMDA-induced oscillations of the same EVN (+TTX/NMDA; $X$. laevis, $n=3 ; X$. petersii, $n=5$ ). EVNs displayed long-lasting depolarizations $\sim 50 \%$ of the time (X. laevis, $n=4 / 7 ; X$. petersii, $n=5 / 11$ ), so we were only able to compare EVN oscillations directly with long-lasting depolarizations in two cells (one in each species). However, all EVNs held stably throughout the protocol, regardless of whether they produced a long-lasting depolarization during fictive calling, oscillated in response to NMDA in the presence of TTX. E, NMDA-induced oscillation duration of EVNs did not differ across species (GLM: $p>0.05$ for all comparisons). $\boldsymbol{F}$, NMDA-induced oscillation period of EVNs did not differ across species (GLM: $p>0.05$ for all comparisons).

in FTNs persist in the absence of network connections, the longer NMDAR-dependent oscillations of X. laevis FTNs compared with $X$. petersii FTNs must be due to intrinsic membrane currents, synaptic currents, or a combination. TTX-insensitive, NMDAR-depen- dent voltage oscillations have been observed in numerous cell types and species, including rodent, fish, turtle, and frog spinal neurons (Wallén and Grillner, 1987; Hochman et al., 1994; MacLean et al., 1997; Guertin and Hounsgaard, 1998; Prime et al., 1999; Masino 
et al., 2012), rat subthalamic neurons (Zhu et al., 2004), hippocampal neurons (Bonansco and Buño, 2003), and layer V pyramidal neurons in mouse (Martell et al., 2012). Along with NMDAR currents, inward currents known to contribute to rhythmic oscillations or rhythmic bursting include voltage-gated calcium currents ( $I_{\text {Cav }}$; Hounsgaard and Kiehn, 1989), calcium-dependent nonselective cation currents $\left(I_{\text {CAN }}\right.$; del Negro et al., 2005; Rubin et al., 2009), persistent sodium currents ( $I_{\mathrm{NaP}}$; del Negro et al., 2002, 2005; Koizumi and Smith, 2008) and $I_{\mathrm{h}}$ (Sharp et al., 1996; Peck et al., 2006). Outward currents underlying oscillations and bursting have also been identified, particularly calcium-dependent potassium currents (El Manira et al., 1994; Cazalets et al., 1999; del Negro et al., 1999; Tahvildari et al., 2008) and voltage-gated potassium currents $\left(I_{\mathrm{Kv}}\right.$; Hess and El Manira, 2001). Because experimental perturbations of these currents can alter the temporal properties of NMDAR-dependent oscillations and bursting (El Manira et al., 1994; Hess and El Manira, 2001; Zhu et al., 2004; Zhong et al., 2007; Mrejeru et al., 2011; Anderson et al., 2012; Wang et al., 2013; Gagnon et al., 2014; Song et al., 2016), they are promising candidates for establishing species-specific FTN properties and Xenopus vocal patterns.

\section{FTNs, but not EVNs, may drive fast trill motor output directly}

Hierarchical clustering and PCA distinguished two groups of premotor vocal neurons in both species: FTNs and EVNs. FTN spikes typically precede each fictive fast trill CAP by several milliseconds; in contrast, EVN spikes that occur during fast trills typically follow or coincide with CAPs. Because $\mathrm{PB}_{\mathrm{X}}$ provides monosynaptic, glutamatergic input to laryngeal motor neurons in $X$. laevis (Zornik and Kelley, 2007) and because some $\mathrm{PB}_{\mathrm{X}}$ vocal neurons project directly to the vocal motor nucleus (Zornik and Yamaguchi, 2012), FTNs are poised to drive fast trill production directly. Because EVN spikes follow or coincide with CAPs, they cannot drive motor output directly.

\section{Potential functions of EVNs in the vocal circuit}

If EVNs do not drive motor output directly, then what role do they play in vocal circuit activity? EVNs and FTNs are sequentially activated, with EVNs spiking before the onset of fast trills and FTNs spiking after the onset of fast trills. Previous research has shown that NMDAR blockade eliminates long-lasting depolarizations in FTNs (Zornik and Yamaguchi, 2012). Before the onset of each fast trill, FTNs receive excitatory inputs (Zornik and Yamaguchi, 2012), which could arise from EVNs. In this scenario, EVNs would serve to depolarize FTNs via glutamatergic EPSPs, leading to activation of NMDA receptors. Because EVNs continue to spike during fictive fast trills, these inputs could serve to maintain an NMDAR-dependent background depolarization in FTNs throughout each fast trill. Similar NMDARdependent background depolarization has been shown to be important for maintaining normal firing rates in other circuits such as the tadpole locomotor circuit (Li and Moult, 2012). Because EVNs often cease spiking before the end of fast trills, the resulting reduction in background excitation could also facilitate the offset of fast trills by allowing FTNs to repolarize. In this scenario, EVNs contribute to both the initiation and the termination of fast trill.

Alternatively, EVNs might be inhibitory. FTNs receive rhythmic inhibitory inputs during fast trills in X. laevis, which serve to maintain synchronous firing of FTNs at fast trill rates (Lawton et al., 2017). In this scenario, EVNs are the source of these inhibitory inputs. Combining physiological analyses with genetic and anatomical characterization will be necessary to reveal the role of EVNs in the Xenopus vocal circuit. In either scenario, $X$. laevis and $X$. petersii share a common vocal circuit element, EVNs, which likely play a role in generating vocal patterns.

\section{Effects of parabrachial area evolution on vertebrate breathing and vocal behaviors}

Our findings complement studies that seek to discover how motor sequencing is regulated in other CPGs such as vertebrate and invertebrate locomotor circuits (Alford and Alpert, 2014; Fushiki et al., 2016; Gunaratne et al., 2017; Li et al., 2014) and the mammalian respiratory complex (Molkov et al., 2013; Guerrier et al., 2015; Kottick and del Negro, 2015). Similar to our discovery of distinct subtypes within $\mathrm{PB}_{\mathrm{X}}$ (EVNs and FTNs) that are sequentially activated during fictive vocalizations, recordings in the Kolliker-Fuse nucleus of the respiratory system have revealed distinct neuronal populations with activity that corresponds to different phases of inspiration and expiration (Dick et al., 1994; Zuperku et al., 2015). These similarities raise the possibility that ancient neural circuits controlling respiratory phases were coopted for related roles in the control of vocal phases. In support of this hypothesis, the vocal premotor nucleus $\mathrm{PB}_{\mathrm{X}}$ is also thought to drive vocal production in the distantly related northern leopard frog, Lithobates pipiens (formerly Rana pipiens; Schmidt, 1992). Further, the parabrachial area also contributes to vocalizations in other vertebrates, including primates (Jürgens, 2002) and bats (Smotherman et al., 2006). Therefore, membrane property evolution of FTN homologs may have shaped vocal patterns across, not only different anurans, but also other vocal vertebrates including ourselves.

\section{References}

Alford ST, Alpert MH (2014) A synaptic mechanism for network synchrony. Front Cell Neurosci 8:290. CrossRef Medline

Anderson TM, Abbinanti MD, Peck JH, Gilmour M, Brownstone RM, Masino MA (2012) Low-threshold calcium currents contribute to locomotor-like activity in neonatal mice. J Neurophysiol 107:103-113. CrossRef Medline

Baltzley MJ, Gaudry Q, Kristan WB Jr (2010) Species-specific behavioral patterns correlate with differences in synaptic connections between homologous mechanosensory neurons. J Comp Physiol A Neuroethol Sens Neural Behav Physiol 196:181-197. CrossRef Medline

Barkan CL, Zornik E, Kelley DB (2017) Evolution of vocal patterns: tuning hindbrain circuits during species divergence. J Exp Biol 220:856-867. CrossRef Medline

Bonansco C, Buño W (2003) Cellular mechanisms underlying the rhythmic bursts induced by NMDA microiontophoresis at the apical dendrites of CA1 pyramidal neurons. Hippocampus 13:150-163. CrossRef Medline

Bumbarger DJ, Riebesell M, Rödelsperger C, Sommer RJ (2013) Systemwide rewiring underlies behavioral differences in predatory and bacterialfeeding nematodes. Cell 152:109-119. CrossRef Medline

Cazalets JR, Sqalli-Houssaini Y, Magoul R (1999) Differential effects of potassium channel blockers on the activity of the locomotor network in neonatal rat. Brain Res 827:185-197. CrossRef Medline

Chiang JT, Steciuk M, Shtonda B, Avery L (2006) Evolution of pharyngeal behaviors and neuronal functions in free-living soil nematodes. J Exp Biol 209:1859-1873. CrossRef Medline

del Negro CA, Hsiao CF, Chandler SH (1999) Outward currents influencing bursting dynamics in guinea pig trigeminal motoneurons. J Neurophysiol 81:1478-1485. CrossRef Medline

del Negro CA, Koshiya N, Butera RJ Jr, Smith JC (2002) Persistent sodium current, membrane properties and bursting behavior of pre-Bötzinger complex inspiratory neurons in vitro. J Neurophysiol 88:2242-2250. CrossRef Medline

del Negro CA, Morgado-Valle C, Hayes JA, Mackay DD, Pace RW, Crowder EA, Feldman JL (2005) Sodium and calcium current-mediated pace- 
maker neurons and respiratory rhythm generation. J Neurosci 25:446453. CrossRef Medline

Dick TE, Bellingham MC, Richter DW (1994) Pontine respiratory neurons in anesthetized cats. Brain Res 636:259-269. CrossRef Medline

Ding Y, Berrocal A, Morita T, Longden KD, Stern DL (2016) Natural courtship song variation caused by an intronic retroelement in an ion channel gene. Nature 536:329-332. CrossRef Medline

El Manira A, Tegnér J, Grillner S (1994) Calcium-dependent potassium channels play a critical role for burst termination in the locomotor network in lamprey. J Neurophysiol 72:1852-1861. CrossRef Medline

Farries MA, Meitzen J, Perkel DJ (2005) Electrophysiological properties of neurons in the basal ganglia of the domestic chick: conservation and divergence in the evolution of the avian basal ganglia. J Neurophysiol 94:454-467. CrossRef Medline

Furman BL, Bewick AJ, Harrison TL, Greenbaum E, Gvoždík V, Kusamba C, Evans BJ (2015) Pan-african phylogeography of a model organism, the african clawed frog 'Xenopus laevis'. Mol Ecol 24:909-925. CrossRef Medline

Fushiki A, Zwart MF, Kohsaka H, Fetter RD, Cardona A, Nose A (2016) A circuit mechanism for the propagation of waves of muscle contraction in Drosophila. Elife 5:e13253. CrossRef Medline

Gagnon A, Walsh M, Okuda T, Choe KY, Zaelzer C, Bourque CW (2014) Modulation of spike clustering by NMDA receptors and neurotensin in rat supraoptic nucleus neurons. J Physiol 592:4177-4186. CrossRef Medline

Gerhardt HC (1994) The evolution of vocalization in frogs and toads. Annu Rev Ecol Syst 25:293-324. CrossRef

Goaillard JM, Taylor AL, Schulz DJ, Marder E (2009) Functional consequences of animal-to-animal variation in circuit parameters. Nat Neurosci 12:1424-1430. CrossRef Medline

Guerrier C, Hayes JA, Fortin G, Holcman D (2015) Robust network oscillations during mammalian respiratory rhythm generation driven by synaptic dynamics. Proc Natl Acad Sci U S A 112:9728-9733. CrossRef Medline

Guertin PA, Hounsgaard J (1998) NMDA-induced intrinsic voltage oscillations depend on L-type calcium channels in spinal motoneurons of adult turtles. J Neurophysiol 80:3380-3382. CrossRef Medline

Gunaratne CA, Sakurai A, Katz PS (2017) Variations on a theme: Species differences in synaptic connectivity do not predict central pattern generator activity. J Neurophysiol 118:1123-1132. CrossRef Medline

Hess D, El Manira A (2001) Characterization of a high-voltage-activated IA current with a role in spike timing and locomotor pattern generation. Proc Natl Acad Sci U S A 98:5276-5281. CrossRef Medline

Hochman S, Jordan LM, MacDonald JF (1994) N-methyl-D-aspartate receptor-mediated voltage oscillations in neurons surrounding the central canal in slices of rat spinal cord. J Neurophysiol 72:565-577. CrossRef Medline

Hounsgaard J, Kiehn O (1989) Serotonin-induced bistability of turtle motoneurones caused by a nifedipine-sensitive calcium plateau potential. J Physiol 414:265-282. CrossRef Medline

Jürgens U (2002) Neural pathways underlying vocal control. Neurosci Biobehav Rev 26:235-258. CrossRef Medline

Katz PS (2016) Evolution of central pattern generators and rhythmic behaviours. Philos Trans R Soc Lond B Biol Sci 371:20150057. CrossRef Medline

Katz PS, Harris-Warrick RM (1999) The evolution of neuronal circuits underlying species-specific behavior. Curr Opin Neurobiol 9:628-633. CrossRef Medline

Kelley DB, Morrell JI, Pfaff DW (1975) Autoradiographic localization of hormone-concentrating cells in the brain of an amphibian, Xenopus laevis. I. Testosterone. J Comp Neurol 164:47-59. CrossRef Medline

Koizumi H, Smith JC (2008) Persistent Na+ and K+-dominated leak currents contribute to respiratory rhythm generation in the pre-Botzinger complex in vitro. J Neurosci 28:1773-1785. CrossRef Medline

Kottick A, del Negro CA (2015) Synaptic depression influences inspiratoryexpiratory phase transition in Dbxl interneurons of the preBötzinger complex in neonatal mice. J Neurosci 35:11606-11611. CrossRef Medline

Lawton KJ, Perry WM, Yamaguchi A, Zornik E (2017) Motor neurons tune premotor activity in a vertebrate central pattern generator. J Neurosci 37:3264-3275. CrossRef Medline

Li WC, Moult PR (2012) The control of locomotor frequency by excitation and inhibition. J Neurosci 32:6220-6230. CrossRef Medline

Li WC, Merrison-Hort R, Zhang HY, Borisyuk R (2014) The generation of antiphase oscillations and synchrony by a rebound-based vertebrate central pattern generator. J Neurosci 34:6065-6077. CrossRef Medline

MacLean JN, Schmidt BJ, Hochman S (1997) NMDA receptor activation triggers voltage oscillations, plateau potentials and bursting in neonatal rat lumbar motoneurons in vitro. Eur J Neurosci 9:2702-2711. CrossRef Medline

Martell AL, Ramirez JM, Lasky RE, Dwyer JE, Kohrman M, van Drongelen W (2012) The role of voltage dependence of the NMDA receptor in cellular and network oscillation. Eur J Neurosci 36:2121-2136. CrossRef Medline

Masino MA, Abbinanti MD, Eian J, Harris-Warrick RM (2012) TTXresistant NMDA receptor-mediated membrane potential oscillations in neonatal mouse $\mathrm{Hb} 9$ interneurons. PLoS One 7:e47940. CrossRef Medline

Molkov YI, Bacak BJ, Dick TE, Rybak IA (2013) Control of breathing by interacting pontine and pulmonary feedback loops. Front Neural Circuits 7:16. CrossRef Medline

Mrejeru A, Wei A, Ramirez JM (2011) Calcium-activated non-selective cation currents are involved in generation of tonic and bursting activity in dopamine neurons of the substantia nigra pars compacta. J Physiol 589: 2497-2514. CrossRef Medline

Newcomb JM, Katz PS (2009) Different functions for homologous serotonergic interneurons and serotonin in species-specific rhythmic behaviours. Proc Biol Sci 276:99-108. CrossRef Medline

Peck JH, Gaier E, Stevens E, Repicky S, Harris-Warrick RM (2006) Amine modulation of Ih in a small neural network. J Neurophysiol 96:29312940. CrossRef Medline

Picker M (1983) Hormonal induction of the aquatic phonotactic response of Xenopus. Behaviour 84:74-90. CrossRef

Prime L, Pichon Y, Moore LE (1999) N-methyl-D-aspartate-induced oscillations in whole cell clamped neurons from the isolated spinal cord of Xenopus laevis embryos. J Neurophysiol 82:1069-1073. CrossRef Medline

Rabbah P, Nadim F (2005) Synaptic dynamics do not determine proper phase of activity in a central pattern generator. J Neurosci 25:11269-11278. CrossRef Medline

Rhodes HJ, Yu HJ, Yamaguchi A (2007) Xenopus vocalizations are controlled by a sexually differentiated hindbrain central pattern generator. J Neurosci 27:1485-1497. CrossRef Medline

Rubin JE, Hayes JA, Mendenhall JL, del Negro CA (2009) Calciumactivated nonspecific cation current and synaptic depression promote network-dependent burst oscillations. Proc Natl Acad Sci U S A 106 : 2939-2944. CrossRef Medline

Ryan MJ, Rand AS (1993) Species recognition and sexual selection as a unitary problem in animal communication. Evolution 47:647-657. CrossRef Medline

Schmidt RS (1992) Neural correlates of frog calling: production by two semi-independent generators. Behav Brain Res 50:17-30. CrossRef Medline

Sharp AA, Skinner FK, Marder E (1996) Mechanisms of oscillation in dynamic clamp constructed two-cell half-center circuits. J Neurophysiol 76:867-883. CrossRef Medline

Simpson HB, Tobias ML Kelley DB (1986) Origin and identification of fibers in the cranial nerve IX-X complex of Xenopus laevis: lucifer yellow backfills in vitro. J Comp Neurol 244:430-444. CrossRef Medline

Smotherman M, Kobayasi K, Ma J, Zhang S, Metzner W (2006) A mechanism for vocal-respiratory coupling in the mammalian parabrachial nucleus. J Neurosci 26:4860-4869. CrossRef Medline

Song SC, Beatty JA, Wilson CJ (2016) The ionic mechanism of membrane potential oscillations and membrane resonance in striatal LTS interneurons. J Neurophysiol 116:1752-1764. CrossRef Medline

Tahvildari B, Alonso AA, Bourque CW (2008) Ionic basis of ON and OFF persistent activity in layer III lateral entorhinal cortical principal neurons. J Neurophysiol 99:2006-2011. CrossRef Medline

Tobias ML, Evans BL, Kelley DB (2011) Evolution of advertisement calls in african clawed frogs. Behaviour 148:519-549. CrossRef Medline

Wallén P, Grillner S (1987) N-methyl-D-aspartate receptor-induced, inherent oscillatory activity in neurons active during fictive locomotion in the lamprey. J Neurosci 7:2745-2755. CrossRef Medline

Wang D, Grillner S, Wallén P (2013) Calcium dynamics during NMDAinduced membrane potential oscillations in lamprey spinal neurons contribution of L-type calcium channels (Ca V1.3). J Physiol 591:2509-2521. CrossRef Medline

Wetzel DM, Haerter UL, Kelley DB (1985) A proposed neural pathway for vocalization in south african clawed frogs, Xenopus laevis. J Comp Physiol A 157:749-761. CrossRef Medline 
Yamaguchi A, Kelley DB (2000) Generating sexually differentiated vocal patterns: laryngeal nerve and EMG recordings from vocalizing male and female african clawed frogs (Xenopus laevis). J Neurosci 20:1559-1567. CrossRef Medline

Yamaguchi A, Cavin Barnes J, Appleby T (2017) Rhythm generation, coordination, and initiation in the vocal pathways of male african clawed frogs. J Neurophysiol 117:178-194. CrossRef Medline

Zhong G, Masino MA, Harris-Warrick RM (2007) Persistent sodium currents participate in fictive locomotion generation in neonatal mouse spinal cord. J Neurosci 27:4507-4518. CrossRef Medline

Zhu ZT, Munhall A, Shen KZ, Johnson SW (2004) Calcium-dependent subthreshold oscillations determine bursting activity induced by N-methylD-aspartate in rat subthalamic neurons in vitro. Eur J Neurosci 19: 1296-1304. CrossRef Medline
Zornik E, Kelley DB (2007) Breathing and calling: neuronal networks in the Xenopus laevis hindbrain. J Comp Neurol 501:303-315. CrossRef Medline

Zornik E, Kelley DB (2008) Regulation of respiratory and vocal motor pools in the isolated brain of Xenopus laevis. J Neurosci 28:612-621. CrossRef Medline

Zornik E, Yamaguchi A (2012) Coding rate and duration of vocalizations of the frog, Xenopus laevis. J Neurosci 32:12102-12114. CrossRef Medline

Zornik E, Katzen AW, Rhodes HJ, Yamaguchi A (2010) NMDAR-dependent control of call duration in Xenopus laevis. J Neurophysiol 103:3501-3515. CrossRef Medline

Zuperku EJ, Prkic I, Stucke AG, Miller JR, Hopp FA, Stuth EA (2015) Automatic classification of canine PRG neuronal discharge patterns using K-means clustering. Respir Physiol Neurobiol 207:28-39. CrossRef Medline 